\title{
How Infants and Young Children Learn About Food: A Systematic Review
}

\author{
Manon Mura Paroche ${ }^{1}$, Samantha J. Caton ${ }^{2}$, Carolus M. J. L. Vereijken ${ }^{1 *}$, Hugo Weenen ${ }^{1}$ \\ and Carmel Houston-Price ${ }^{3}$ \\ ${ }^{1}$ Danone Nutricia Research, Utrecht, Netherlands, ${ }^{2}$ School of Health and Related Research, Section of Public Health, \\ University of Sheffield, Sheffield, United Kingdom, ${ }^{3}$ School of Psychology and Clinical Language Sciences, University of \\ Reading Malaysia, Iskandar Puteri, Malaysia
}

\section{OPEN ACCESS}

Edited by: Caroline Braet,

Ghent University, Belgium

Reviewed by:

Stephanie Anzman-Frasca, University at Buffalo, United States

Laura Nynke Van Der Laan, Utrecht University, Netherlands

*Correspondence:

Carolus M. J. L. Vereijken carel.vereijken@danone.com

Specialty section: This article was submitted to Eating Behavior, a section of the journal Frontiers in Psychology

Received: 16 February 2017 Accepted: 08 June 2017 Published: 25 July 2017

Citation:

Mura Paroche M, Caton SJ, Vereijken CMJL, Weenen $\mathrm{H}$ and Houston-Price C (2017) How Infants and Young Children Learn About

Food: A Systematic Review.

Front. Psychol. 8:1046

doi: 10.3389/fpsyg.2017.01046
Early childhood is a critical time for establishing food preferences and dietary habits. In order for appropriate advice to be available to parents and healthcare professionals it is essential for researchers to understand the ways in which children learn about foods. This review summarizes the literature relating to the role played by known developmental learning processes in the establishment of early eating behavior, food preferences and general knowledge about food, and identifies gaps in our knowledge that remain to be explored. A systematic literature search identified 48 papers exploring how young children learn about food from the start of complementary feeding to 36 months of age. The majority of the papers focus on evaluative components of children's learning about food, such as their food preferences, liking and acceptance. A smaller number of papers focus on other aspects of what and how children learn about food, such as a food's origins or appropriate eating contexts. The review identified papers relating to four developmental learning processes: (1) Familiarization to a food through repeated exposure to its taste, texture or appearance. This was found to be an effective technique for learning about foods, especially for children at the younger end of our age range. (2) Observational learning of food choice. Imitation of others' eating behavior was also found to play an important role in the first years of life. (3) Associative learning through flavor-nutrient and flavor-flavor learning (FFL). Although the subject of much investigation, conditioning techniques were not found to play a major role in shaping the food preferences of infants in the post-weaning and toddler periods. (4) Categorization of foods. The direct effects of the ability to categorize foods have been little studied in this age group. However, the literature suggests that what infants are willing to consume depends on their ability to recognize items on their plate as familiar exemplars of that food type.

Keywords: infant, toddler, food preference, learning, eating habits, development

\section{INTRODUCTION}

The first years of life are marked by tremendous physical and psychological developments, allowing infants to gradually become less helpless and more independent. During this period, infants show rapid advances in their language skills, social awareness, and cognitive capacity for attention and learning (Snow and McGaha, 2003; Goswami, 2008a,b). At the same time, infants undergo 
significant developments in the eating domain, with the transition from a complete reliance on milk, underpinned by the newborn infant's well-organized sucking reflex, to the omnivore eating behavior of the toddler. The start of this transition is the onset of weaning, when the infant is first introduced to solid foods. Complementary feeding is usually recommended to occur at around 6 months (World Health Organization, 2009; British Dietetic Association, 2016), although some suggest that weaning might begin at any time between 4 and 6 months (e.g., European Society for Pediatric Gastroenterology Hepatology and Nutrition; Agostoni et al., 2008). Regardless of such official guidelines, some parents introduce solid foods even earlier, some as early as 8 weeks of age (Caton et al., 2011). At first, children do not make their own food choices but rely on their caregivers to provide them with appropriate foods. Within 3 or 4 years, the child establishes autonomous feeding behavior, and sets boundaries on the foods they will accept (Hammer, 1992). The "food learning" journey is therefore characterized by a gradual change from total dependence on caregivers prior to weaning to the child becoming an accomplished eater, making independent food choices albeit limited by the context of what is available (Vereijken et al., 2011). The eating behaviors established during this early period track into adolescence and adulthood and, when they are healthy behaviors, may have a positive influence in combatting noncommunicable diseases (Skinner et al., 2002; Vereecken et al., 2004; Coulthard et al., 2010).

Importantly, while human infants show similar affective responses toward different taste stimuli across cultures, suggesting a biological underpinning for the foods we are programmed to prefer and avoid (Mennella and Ventura, 2011), infants actually begin life with very few innate taste preferences, and a strong capacity to learn to like new foods (Davis, 1939). The environment-and the family home in particular-play a crucial role in shaping children's eating behaviors (Kral and Faith, 2007). It has been suggested that the introduction of complementary feeding is the most important time for learning about new foods, as it is during this period that the child's senses are suddenly exposed to a variety of new types of stimulation (Lipsitt et al., 1985). Cashdan (1994) found that children younger than 24 months of age were more receptive to new foods than older children, and recommended that parents should introduce new foods at this time. These suggestions support Kolb's (1984) view of the first 3 years of life as a sensitive period for the development of "perception, cognition, behaviors and experiences" in relation to food.

If the period from weaning to around 3 years of age is indeed of major importance for learning about food and developing lifelong preferences, the effective promotion of healthy eating habits in this age group would be facilitated by a better understanding of the mechanisms that support children's learning. A seminal paper by Birch and Anzman (2010) identified three learning processes relevant to children's early learning about food and eating (see also Birch and Doub, 2014). Familiarization refers to the positive impact of repeated exposure on liking of the exposed stimulus (Zajonc, 1968). Associative learning or conditioning occurs when a positive evaluation of a stimulus arises through its association with a second, already-liked stimulus (Birch and Anzman, 2010). Observational learning or social learning refers to the natural human inclination to observe and imitate the behaviors of others (Bandura, 1977). Birch and Anzman (2010; see also Birch and Doub, 2014) show that these three learning theories each play a role in young children's learning about food. Other work suggests that categorization processes-the mental grouping together of stimuli into categories and schemas (Rakison and Oakes, 2003) - also play an important role in children's learning about foods (Nguyen, 2007b). Despite the importance of this area, no systematic review has so far been conducted of the literature relating to the learning processes involved in infants' developing knowledge of food between weaning and 3 years of age. This review aims to fill this gap.

Following Kolb (1984), we consider "learning" to include developments in children's perception, cognition, behavior and experiences in relation to food. Within the target group and age range (human infants between weaning and 36 months), we include all possible aspects of what has to be learned about food. This includes amongst others:

a) A food's evaluative status (whether it is liked or disliked, healthy or unhealthy);

b) Perhaps most importantly, which foods the child will accept into their diet;

c) How foods are recognized based on their physical characteristics (taste, smell, texture and appearance);

d) The origins of foods (e.g., whether they are plant or animal products), and how they are prepared;

e) The names of food ingredients, preparation processes, utensils, etc.;

f) The contexts in which foods are eaten (appropriate times or occasions, quantities and combinations);

g) How foods are eaten (including oral-motor skills, regulation of food intake, mealtime etiquette);

h) The post-ingestive consequences of consuming foods (whether they are satiating, provide energy, cause nausea, are unsafe or inedible).

In summary, the goal of this systematic review is to provide an overview of the developmental processes that are relevant to how children learn about food. We summarize the relevant empirical evidence in relation to each process (from the start of complementary feeding to 36 months of age), and define the key gaps in the literature that need to be addressed if we are to increase our understanding of early food-related behavior.

\section{METHODOLOGY}

The literature search, screening and clustering methods employed in the systematic review are summarized in Figure 1 and described in more detail below.

\section{Literature Search}

The goal of the systematic review was to identify the role played by developmental learning processes in how children learn about food from weaning to 36 months of age. Three groups of search terms were defined: one for "food," one for "learning process" 


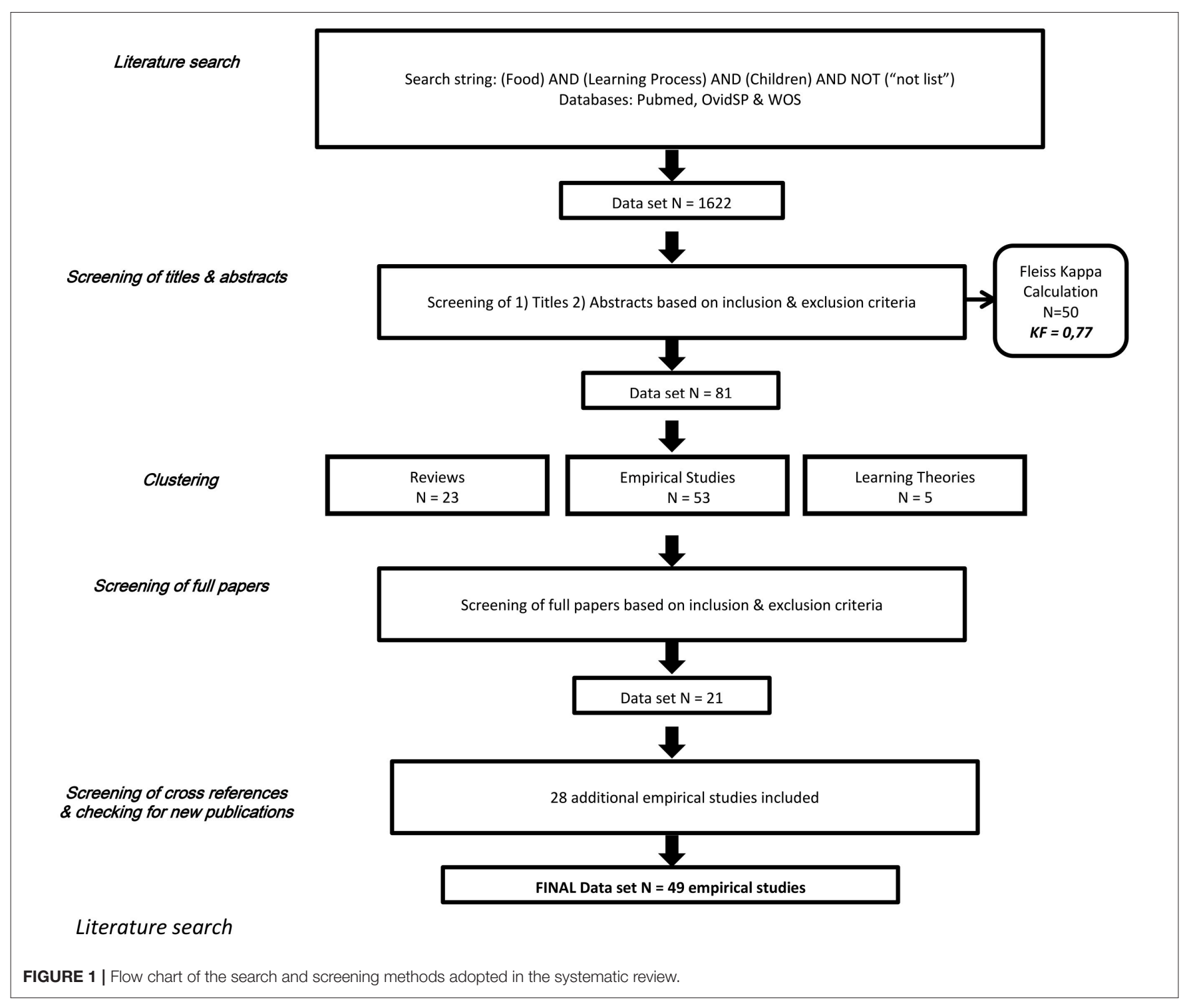

and one for "children." For "learning process" the list of search terms included terms relating to all learning theories known to the authors. The list of keywords used as search strings can be seen in Table 1. As a preliminary search generated a large number of irrelevant articles, a "NOT list" of search terms was generated by the authors on the basis of the preliminary search (see Table 1). The search was limited to peer-reviewed articles written in English. The initial literature search was conducted first in February 2012, and then repeated in February 2016, using OvidSP, Pubmed and Web of Science. The initial search resulted in a total of 1622 papers (853 from OvidSP, 811 from Web of Science and 59 from PubMed).

\section{Screening of Titles and Abstracts}

The titles and abstracts of the articles identified by the literature search were screened by hand using the following inclusion and exclusion criteria:

\section{Populations}

Articles addressing healthy children from weaning to 36 months old were included. Studies with fewer than five participants or involving animals were excluded, as were studies with a clinical or disease focus. Studies of food refusal, picky eating and other non-clinical "problematic" feeding behaviors were included.

\section{Focus}

Only articles relevant to a learning process in the food domain were included. Articles dealing with the pre-weaning milkfeeding period were excluded, as were studies focusing on the learning shown by parents, rather than children.

\section{Type of Article}

Only articles that were published in English, with named authors, and subject to international peer review were included. Studies focusing on the development of a methodology were excluded, as were conference abstracts and position papers. 
TABLE 1 | Search strings used in the literature search.

Search in Title and Abstract

Search term 1: FOOD (feed or food or eat* or taste or intake)

Search term 2: (AND) LEARNING (habits or socialization or socialization or enculturation or cognit or social learning or conditioning or imitation or categorization or categorization or programming or schemas or script* or modeling or preference)

Search term 3: (AND) CHILDREN (baby or infant or infancy or child* or early life or toddler*)

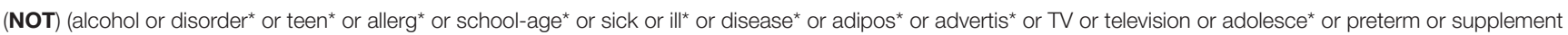
or vaccine or autism or dysphagia or defiency or policy or chimpanzee* or birth weight or colonization or rat* or sport or physical activity or cancer or carcino* or cost* or poverty or prenatal or pregnan* or HIV or education or school program or school or education program* or adult* or older or elder or elderly or subject or women or men or gender or blood concentration or plasma concentration or carries or caries or dentifrice or fluor ${ }^{*}$ or disable* or fish* or vitamin D or low income or zinc or copper or nitrate or PCB)

(AND) Peer reviewed

(AND) English language

Screening involved two steps. The first step involved screening titles; this reduced the set of papers to 366. The second step involved screening of abstracts; this reduced the set of papers to 81 .

\section{Checking the Reliability of Screening}

To check inter-rater reliability, 50 papers were randomly selected from the 366 articles remaining after the first step in the screening process. Four of the authors completed step two for these 50 papers, each making an independent judgment about their inclusion. The Fleiss's Kappa statistic $(\mathrm{FK}=0.77)$ indicated an acceptable level of reliability between their judgments. Disagreements were discussed and a consensus reached in all cases. The remaining papers from step one were then assessed by the first author and a second assessor.

\section{Clustering}

To facilitate the structure of the review, papers that passed screening were clustered. Four clusters were identified, each representing a separate learning process: (1) Familiarization; (2) Observational learning; (3) Associative learning; (4) Categorization. The choice of these clusters was based on a preliminary screening of the selected papers and on the learning processes previously identified as involved in the development of eating habits (Nguyen and Murphy, 2003; Birch and Anzman, 2010).

\section{Screening of Full Articles}

Two authors were assigned to each of the learning theories. Both authors read all of the articles in their category and excluded any article that was deemed not relevant to how children learn about food. Articles that included participants older than 3 years were not excluded if they also included younger participants. Only reports of empirical studies were included. Screening reduced the set of relevant articles to 20 .

\section{Addition of Further Articles Through Cross-Referencing and Checking for New Publications}

Further articles were identified through their citation in the papers found in the literature search or because they cited papers found in the search. 17 additional articles were found that satisfied our inclusion/exclusion criteria. A second iteration of the literature search and screening process was conducted in February 2016, following exactly the same process as the first search; this identified 11 newly-published articles that satisfied our inclusion/exclusion criteria and these were added to the set. The final set of articles considered in the review consists of 48 papers (see Tables 2-5).

\section{Quality Assessment}

Articles were assessed for quality using assessment criteria adapted from Jackson et al. (2008). Quality criteria were based on whether the article provided a clear description/explanation of: (1) the design; (2) the scientific background and rationale; (3) the hypotheses and objectives; (4) the sample; (5) the data analysis; (6) the findings in relation to the hypotheses and objectives; (7) the provision of attrition/exclusion data, and appropriate handling of missing data; (8) the appropriateness of the procedure; (9) consideration of methodological strengths; (10) consideration of the limits of the study; and (11) the study's relevance for theories of learning about food. As such quality criteria are necessarily subjective we used them only to exclude low-scoring outliers in terms of the total scores awarded. Two authors independently rated each paper and discussed any disagreements until consensus was reached. Quality assessment (QA) scores ranged from 3 to 11 (out of a maximum of 11); 48 papers were awarded scores of 6 or higher, satisfying the majority of the rated criteria. One paper received an outlying score of 3 and was excluded from further consideration. Quality assessment (QA) ratings are provided in Tables 2-5, which list the articles relevant to each of the learning theories of interest. 

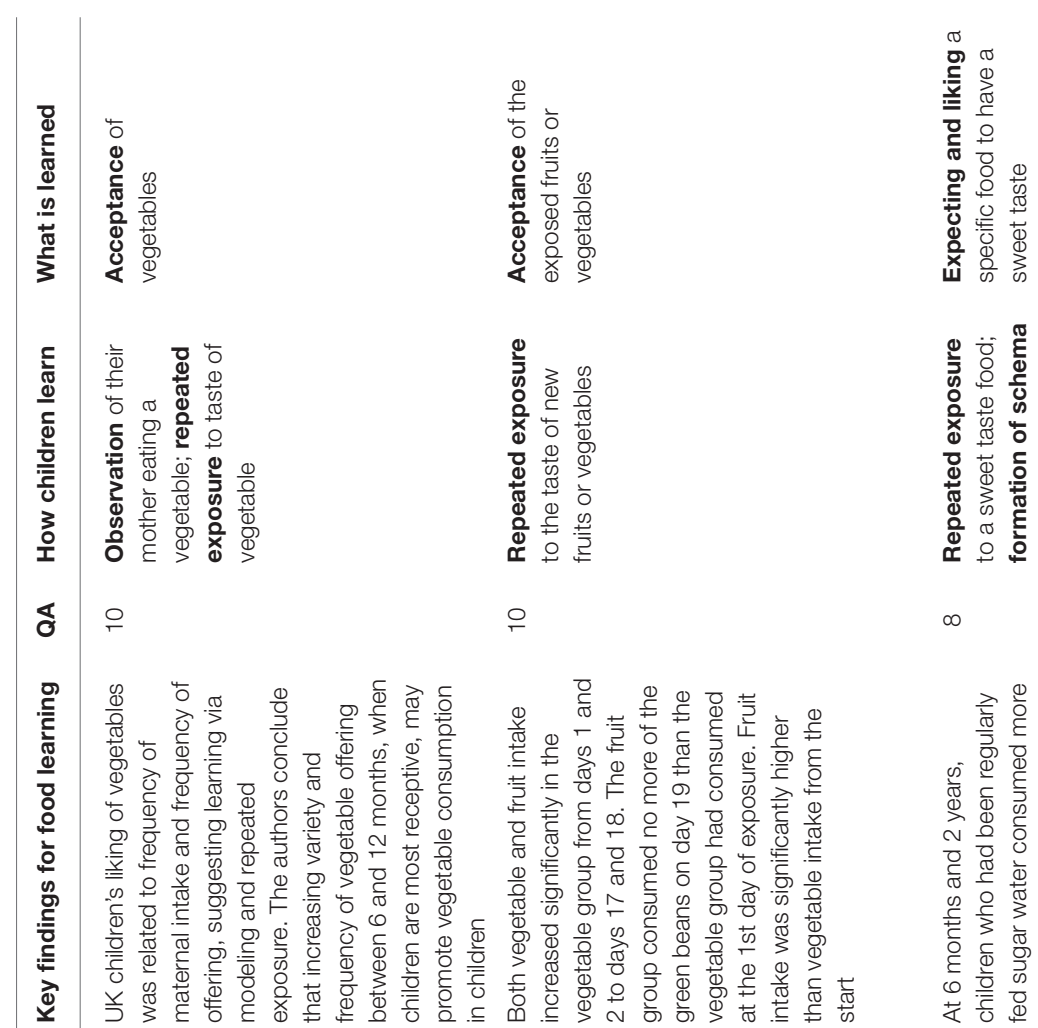

우
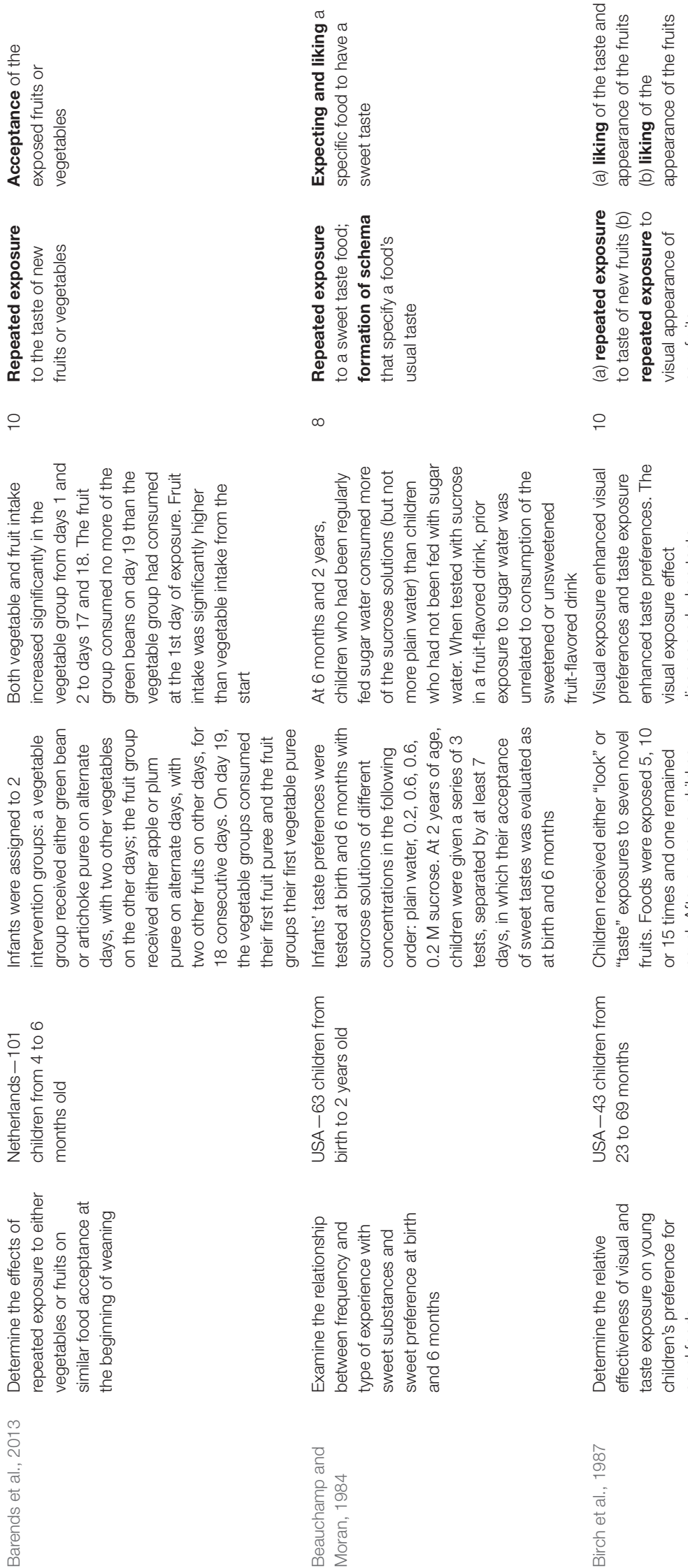

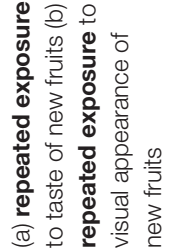

우

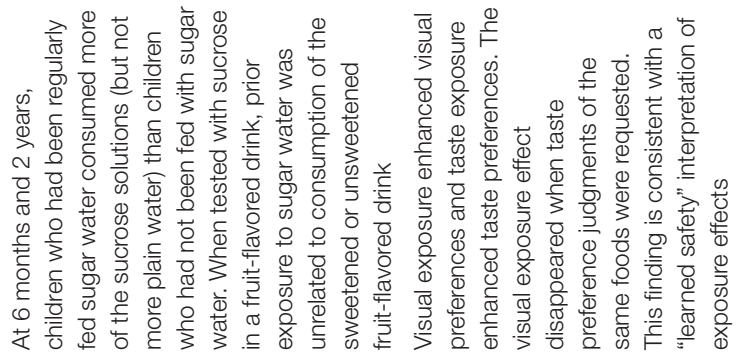

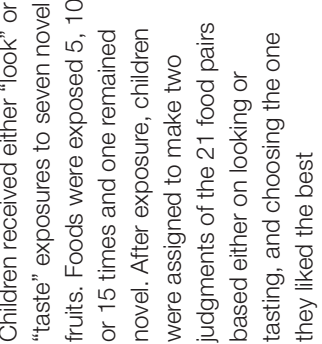

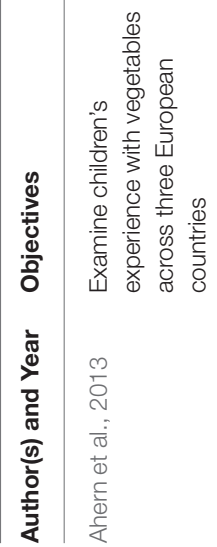

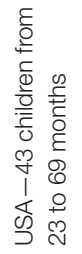

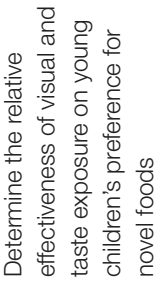



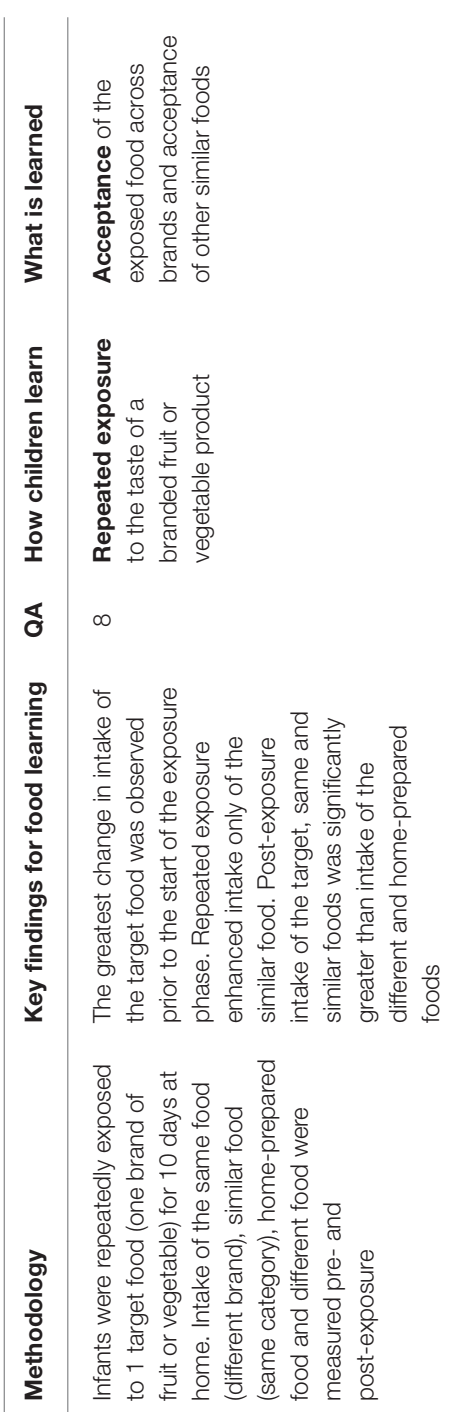

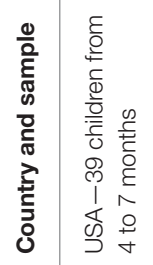
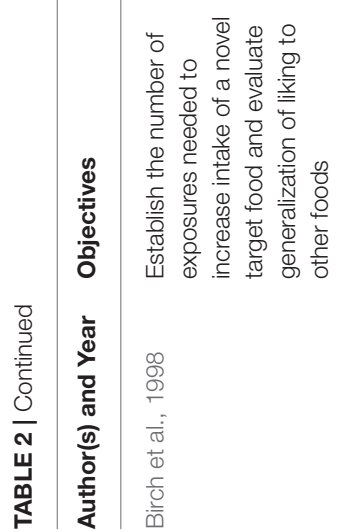
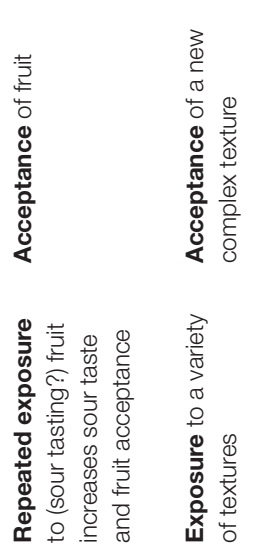

๑

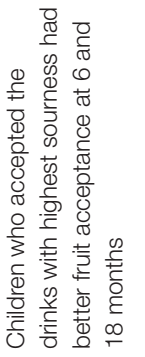

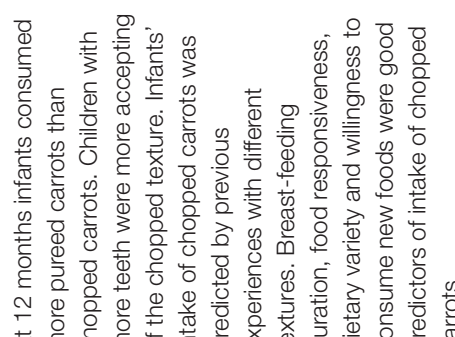
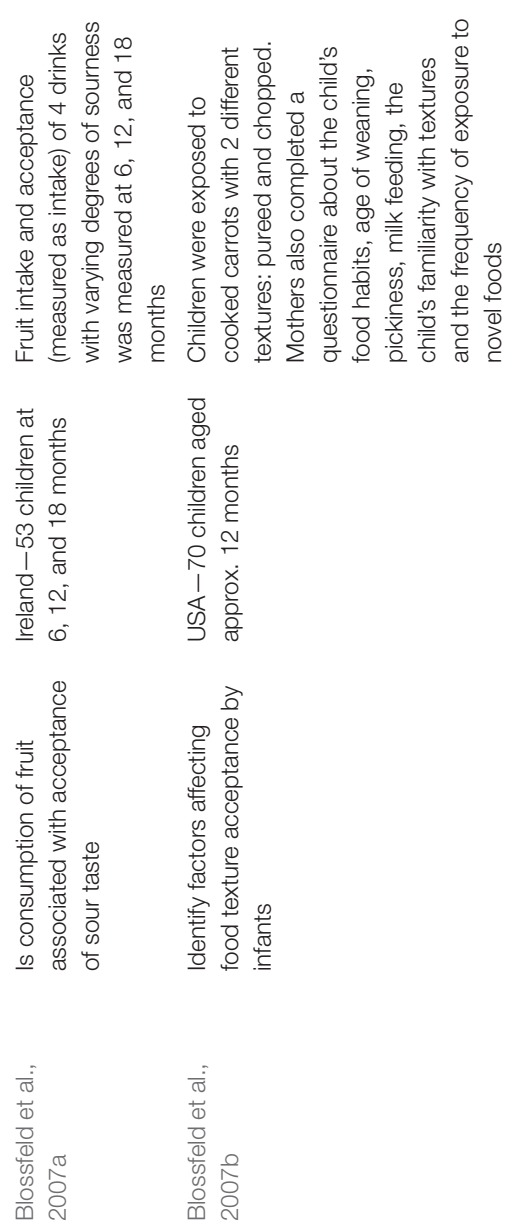
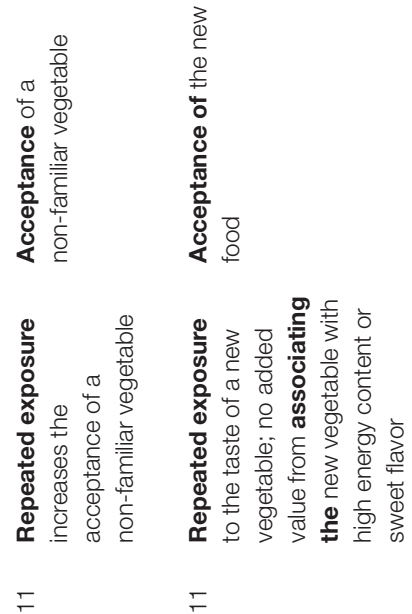

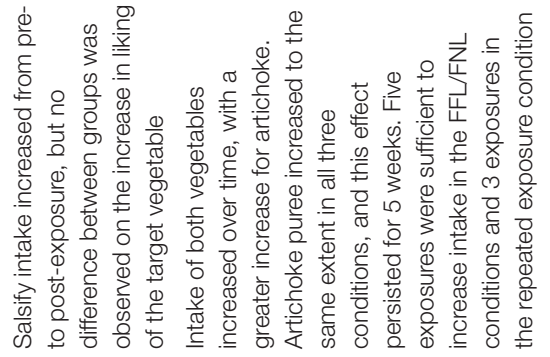
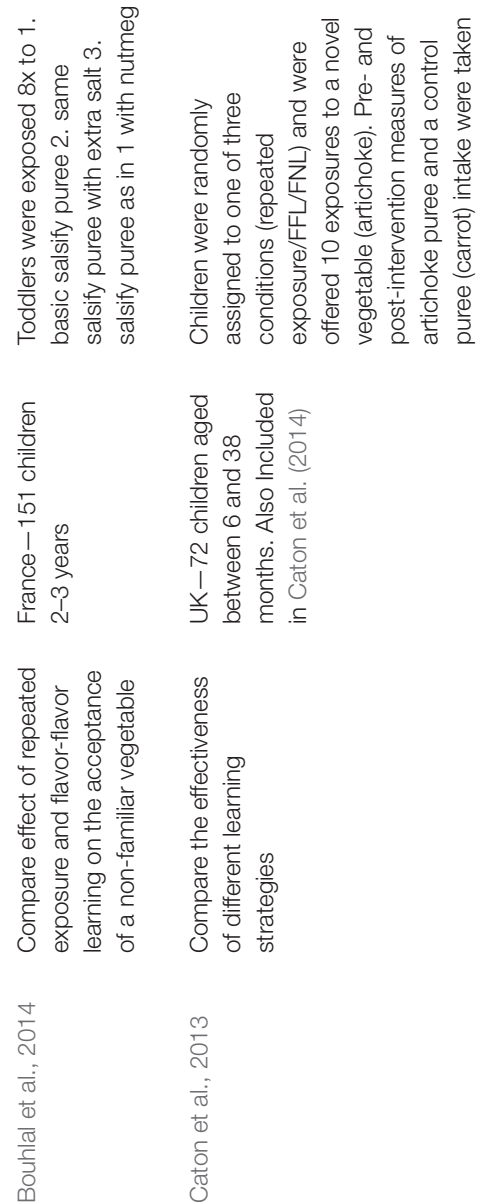


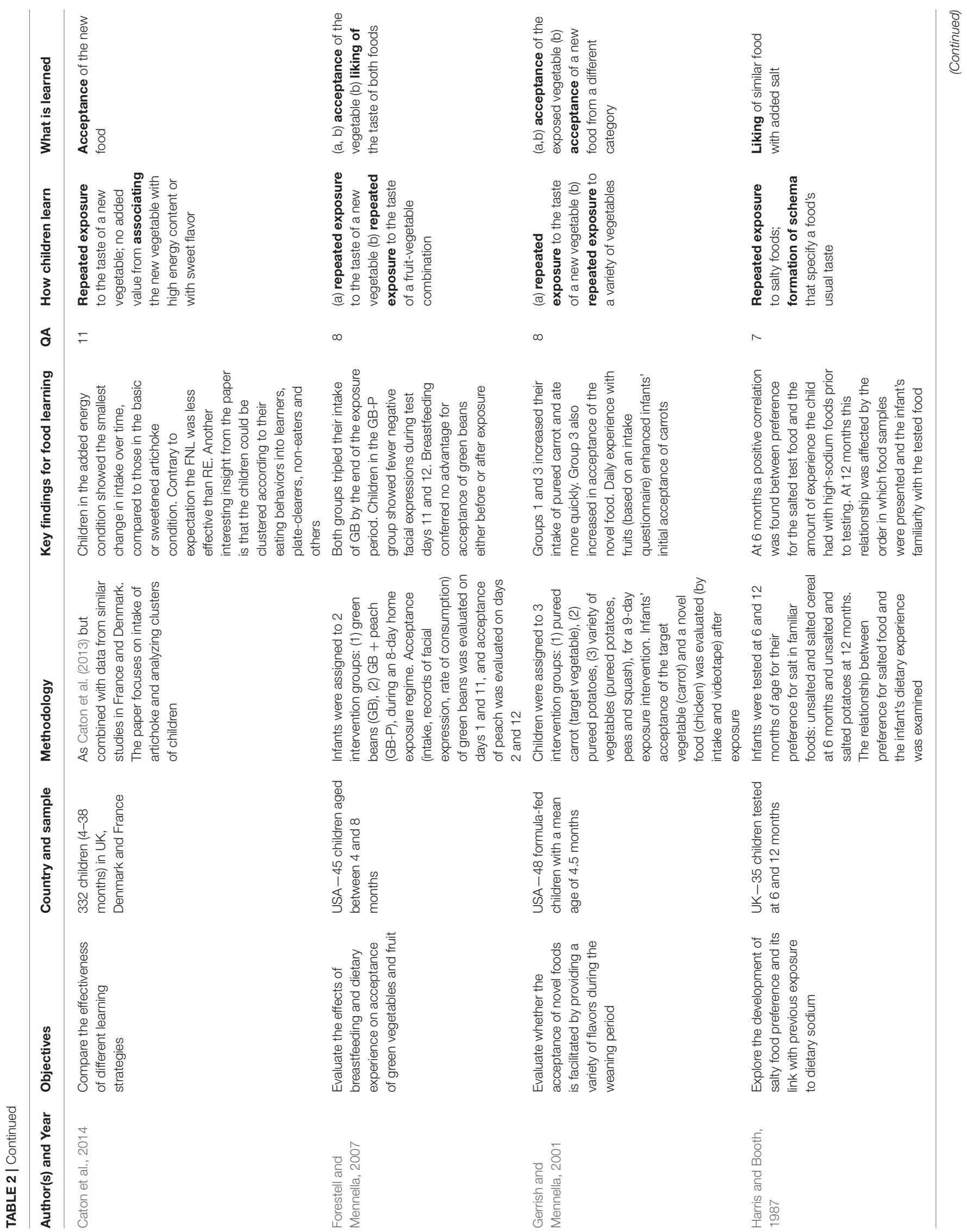




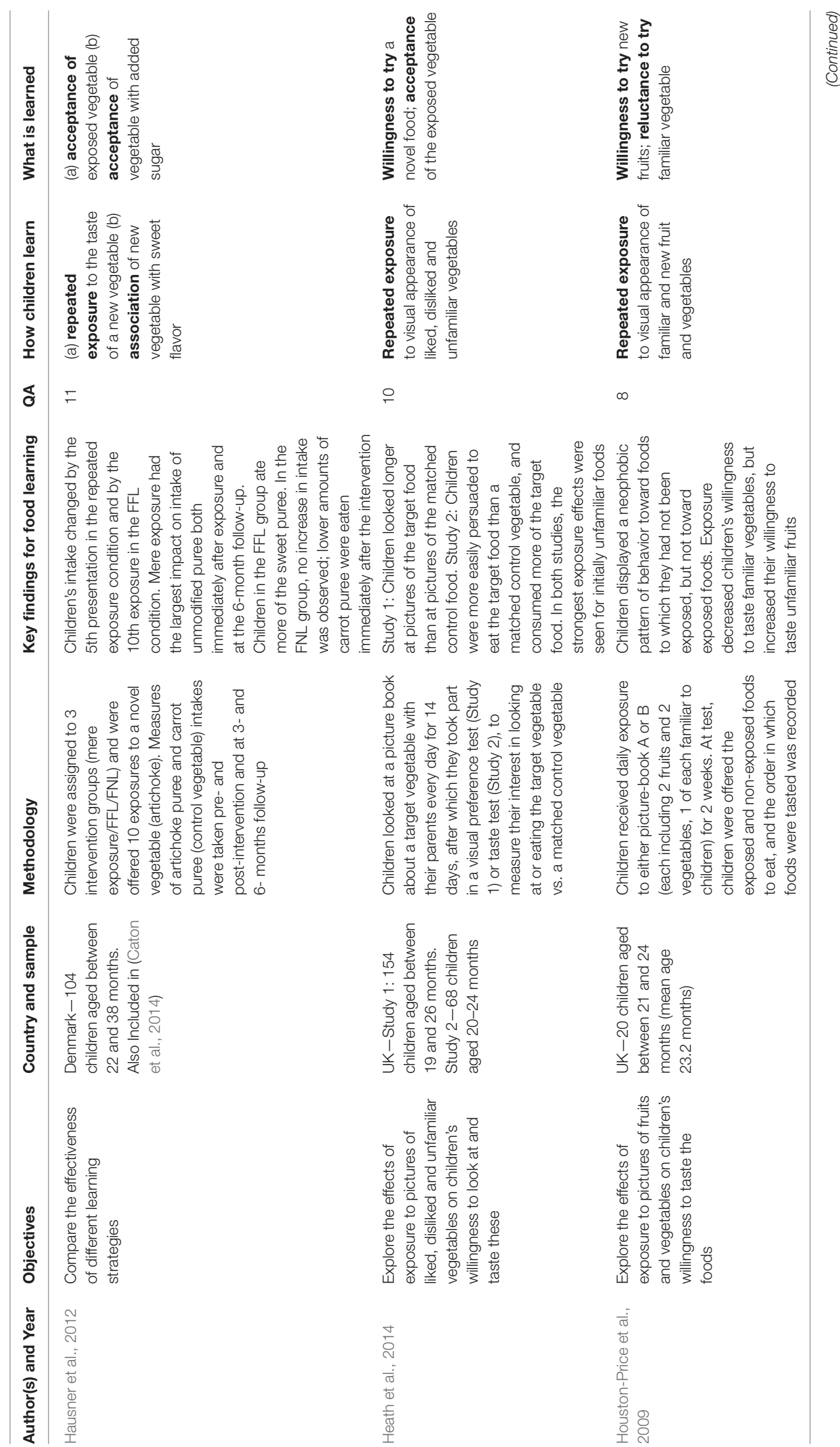




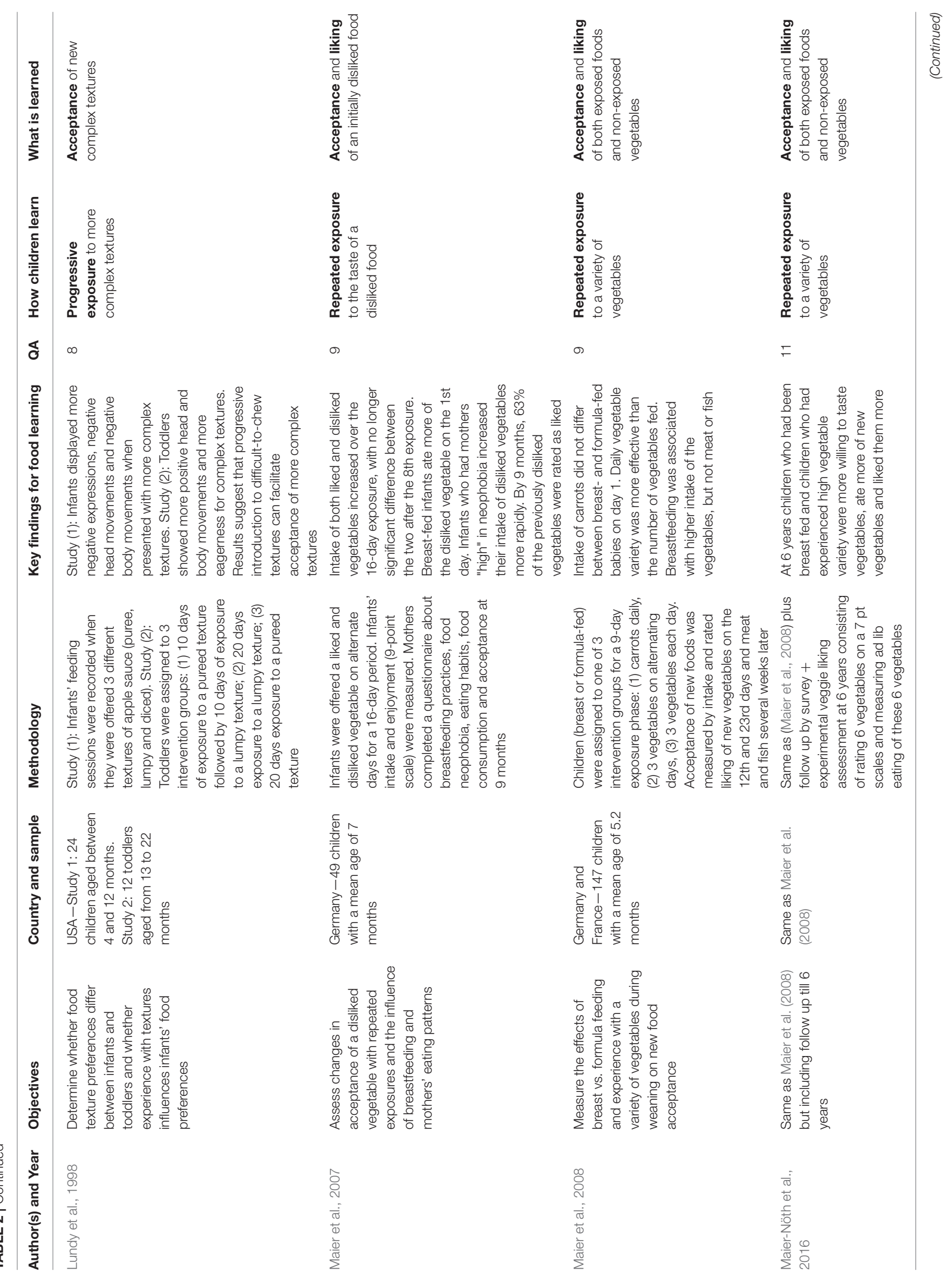




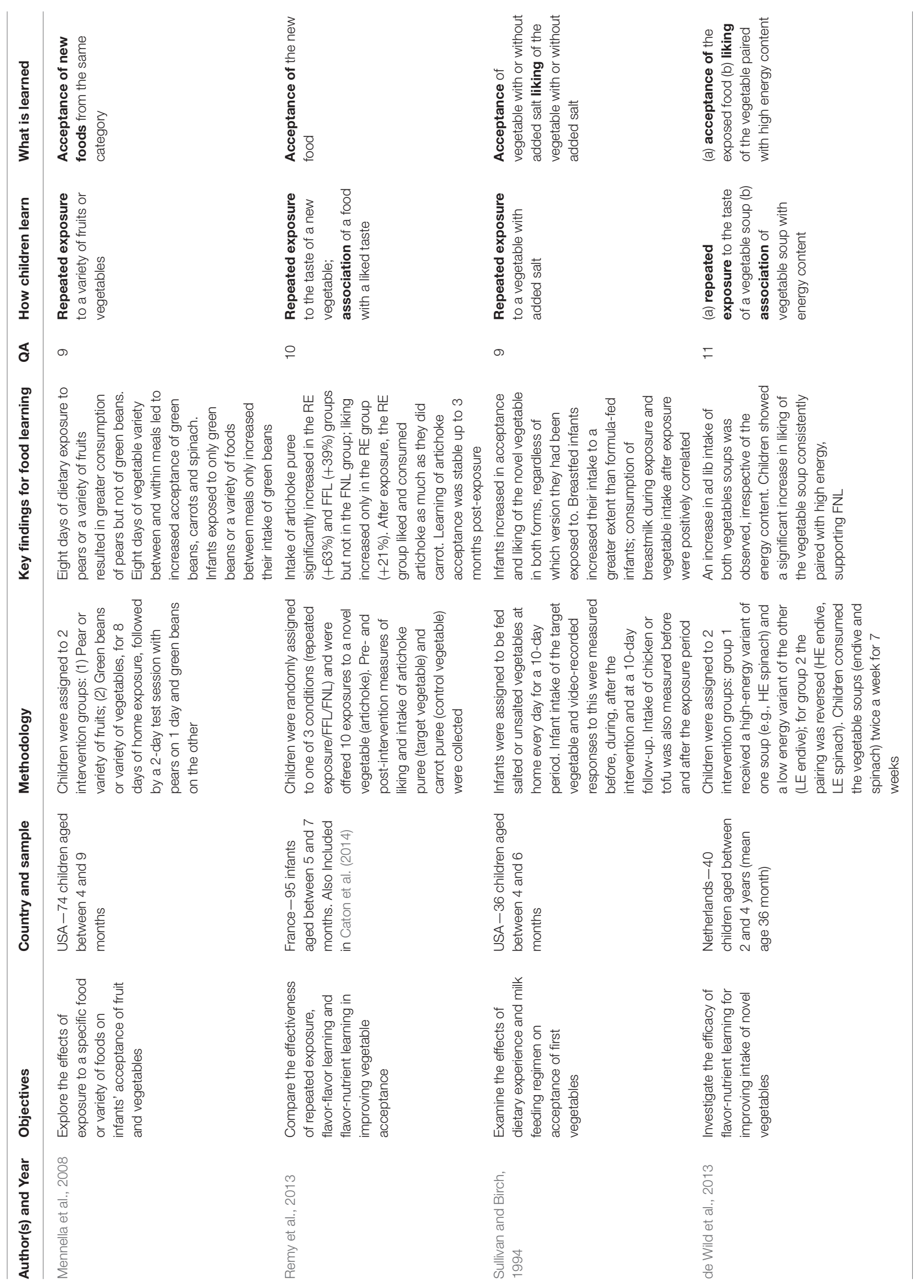




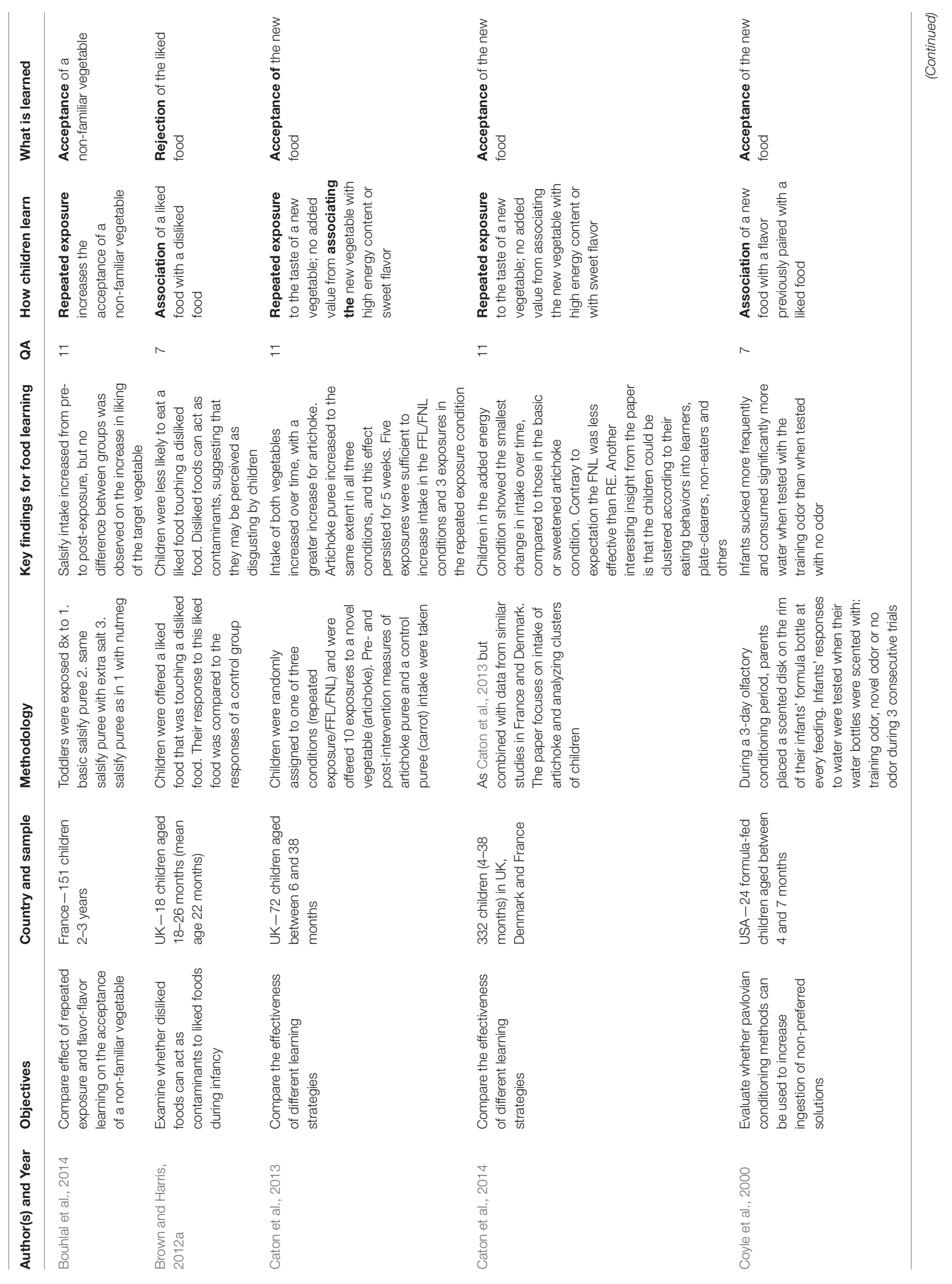




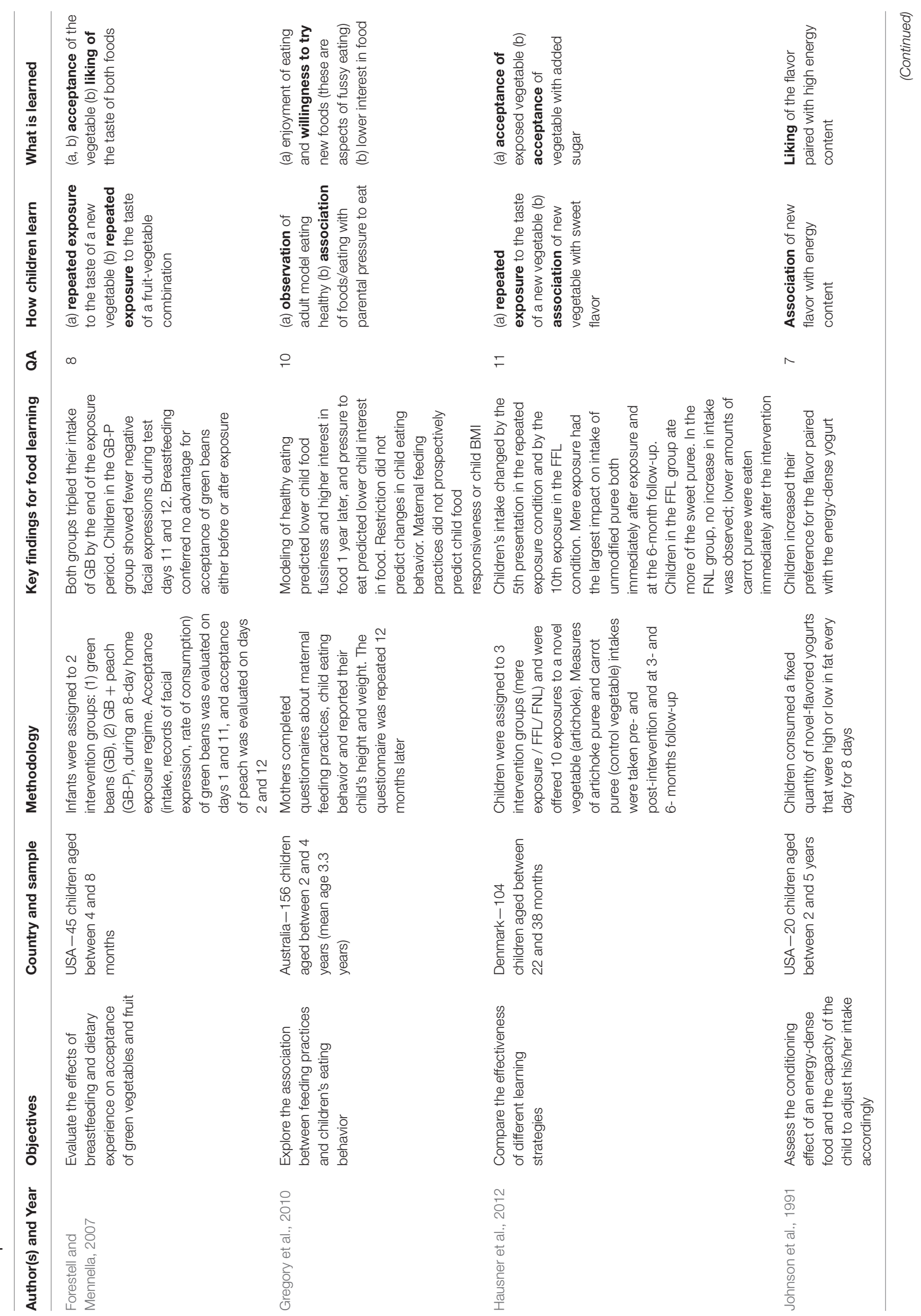




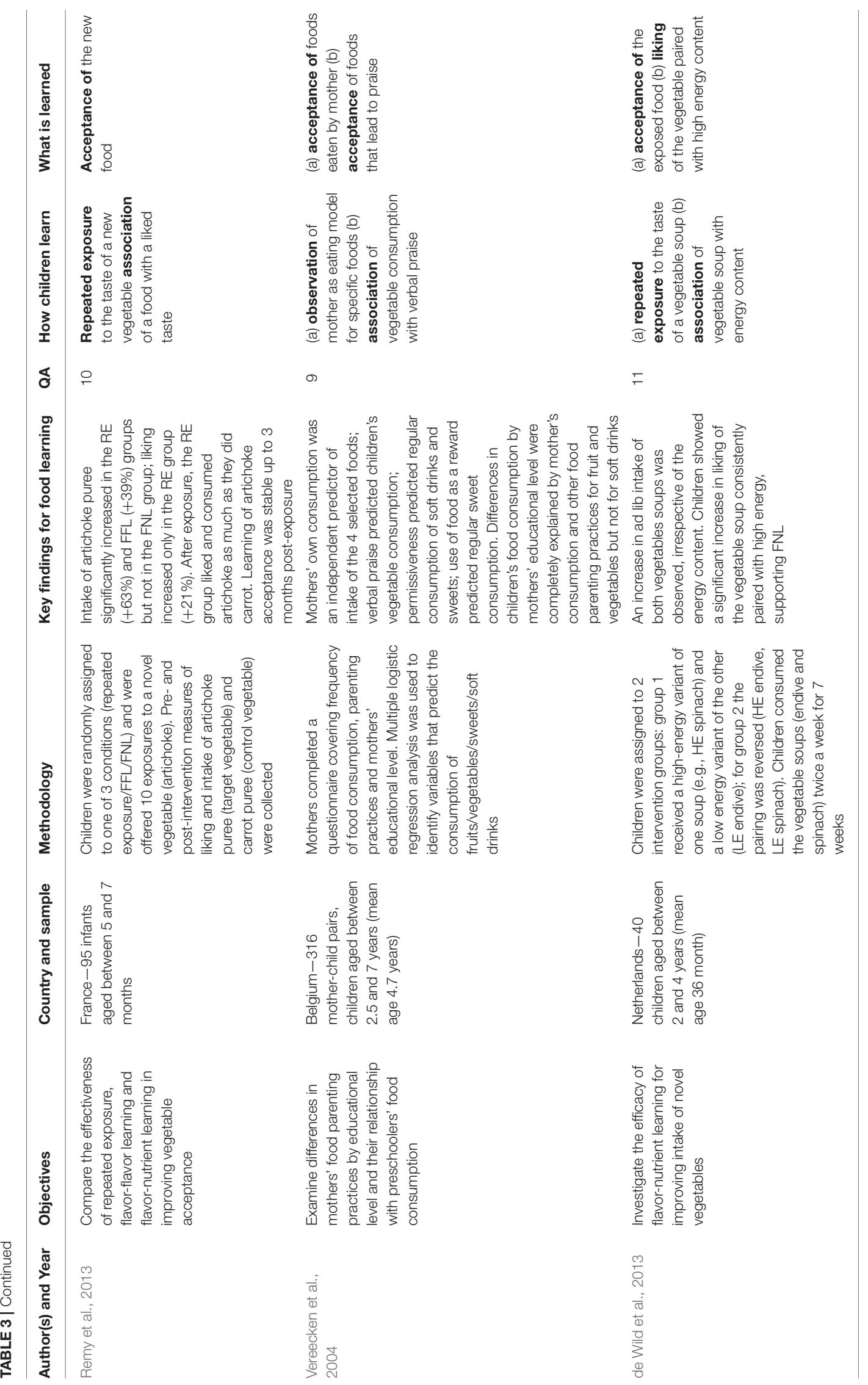




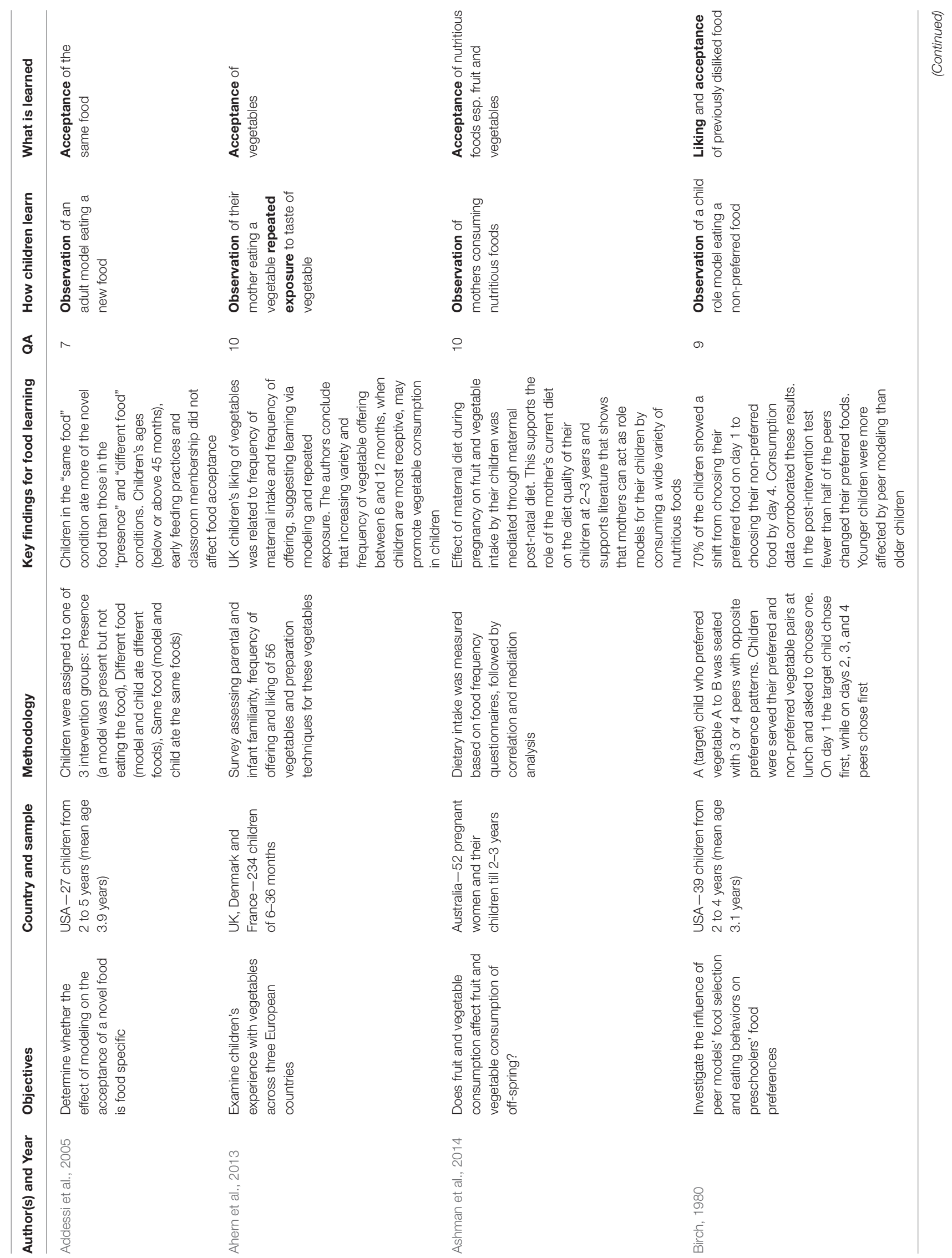




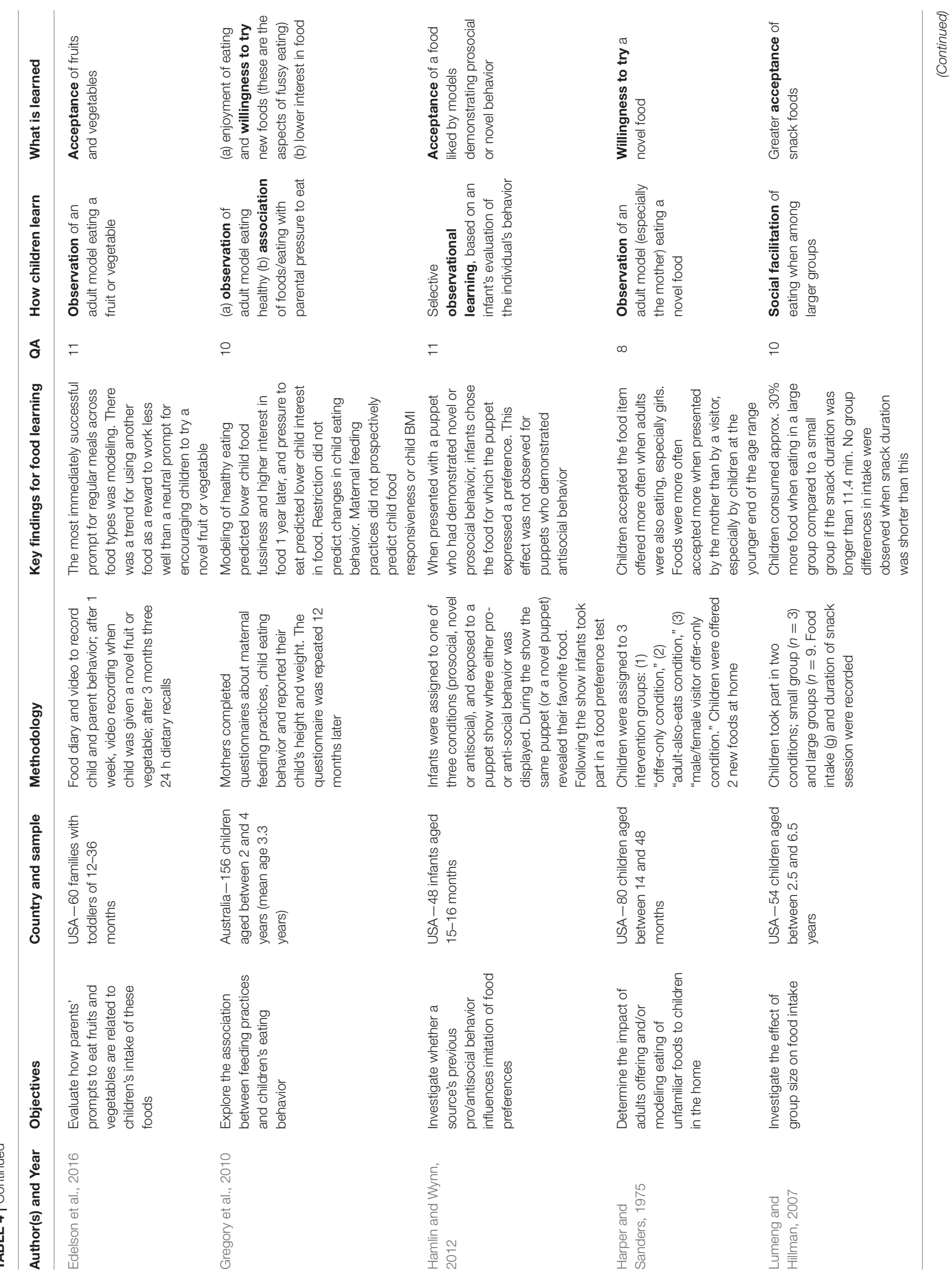




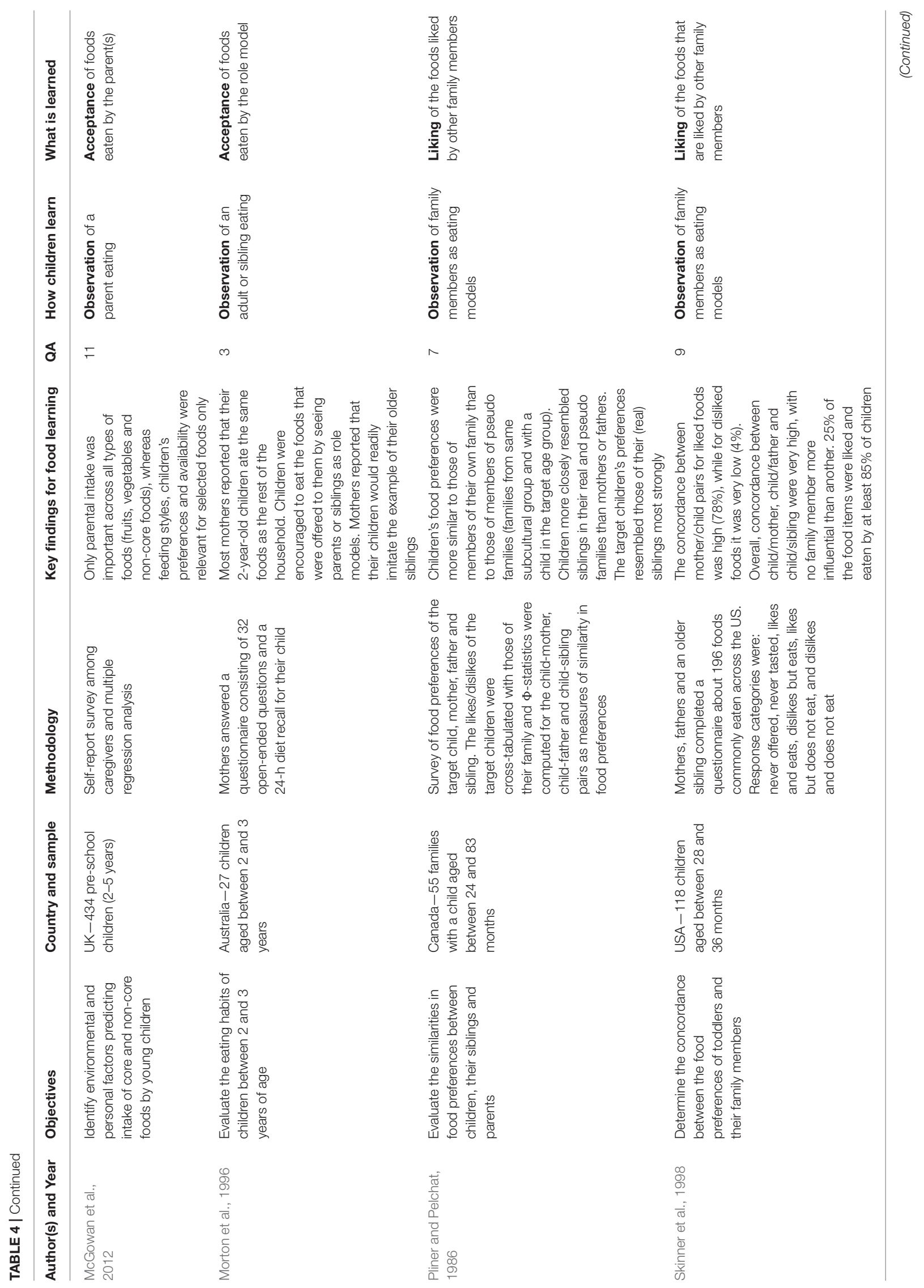




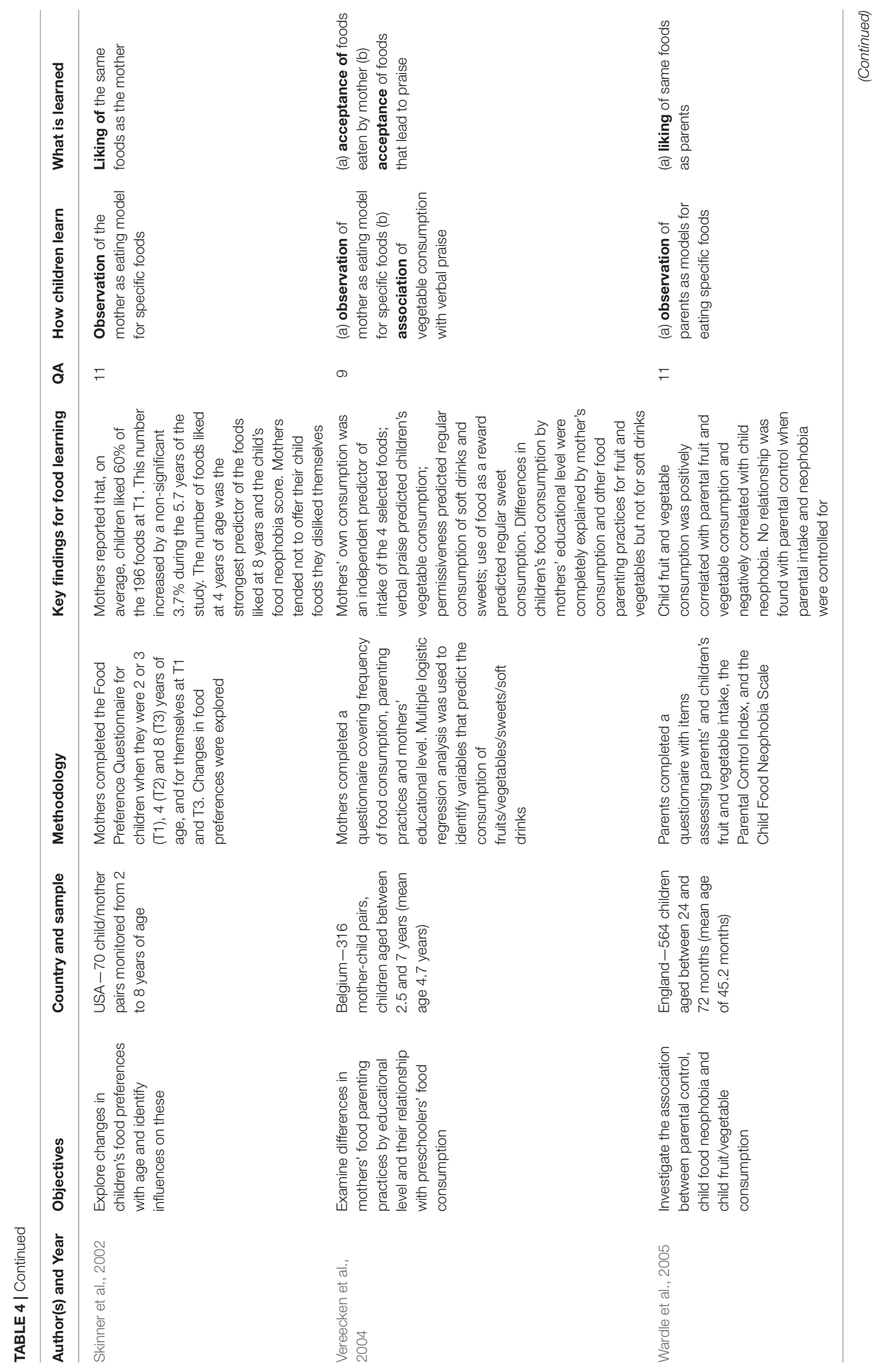




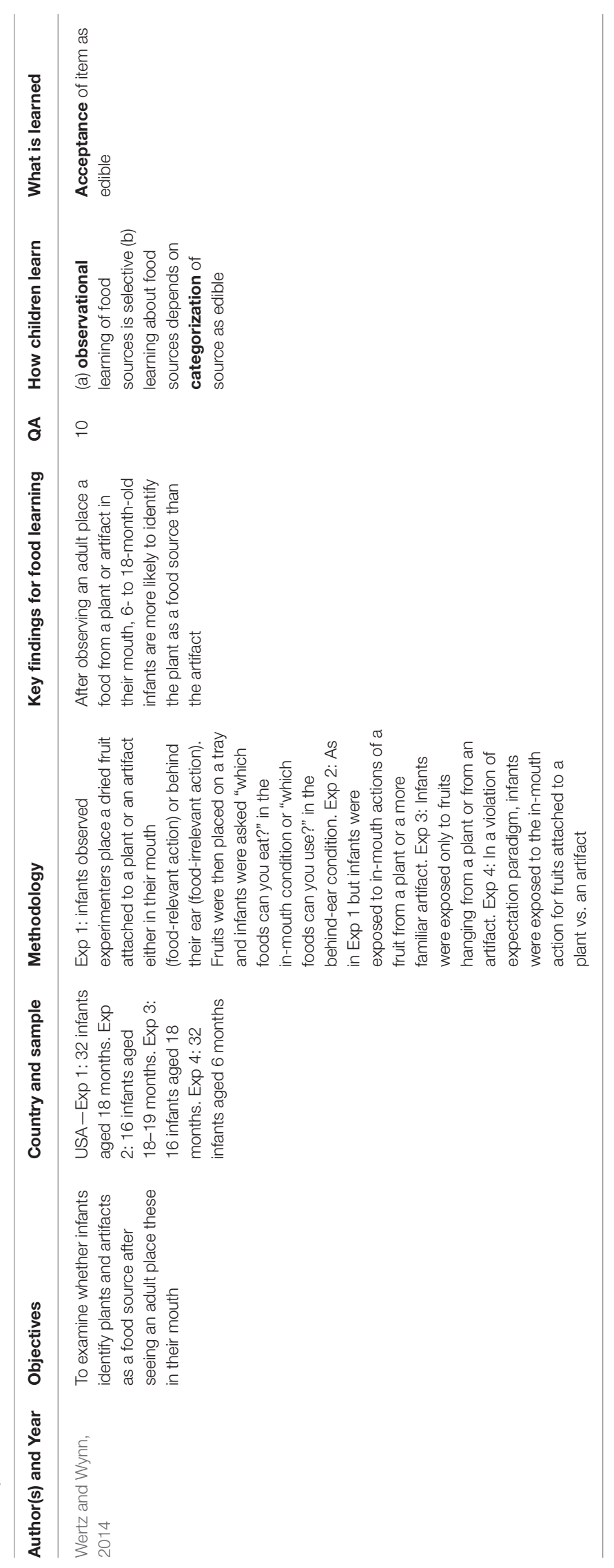




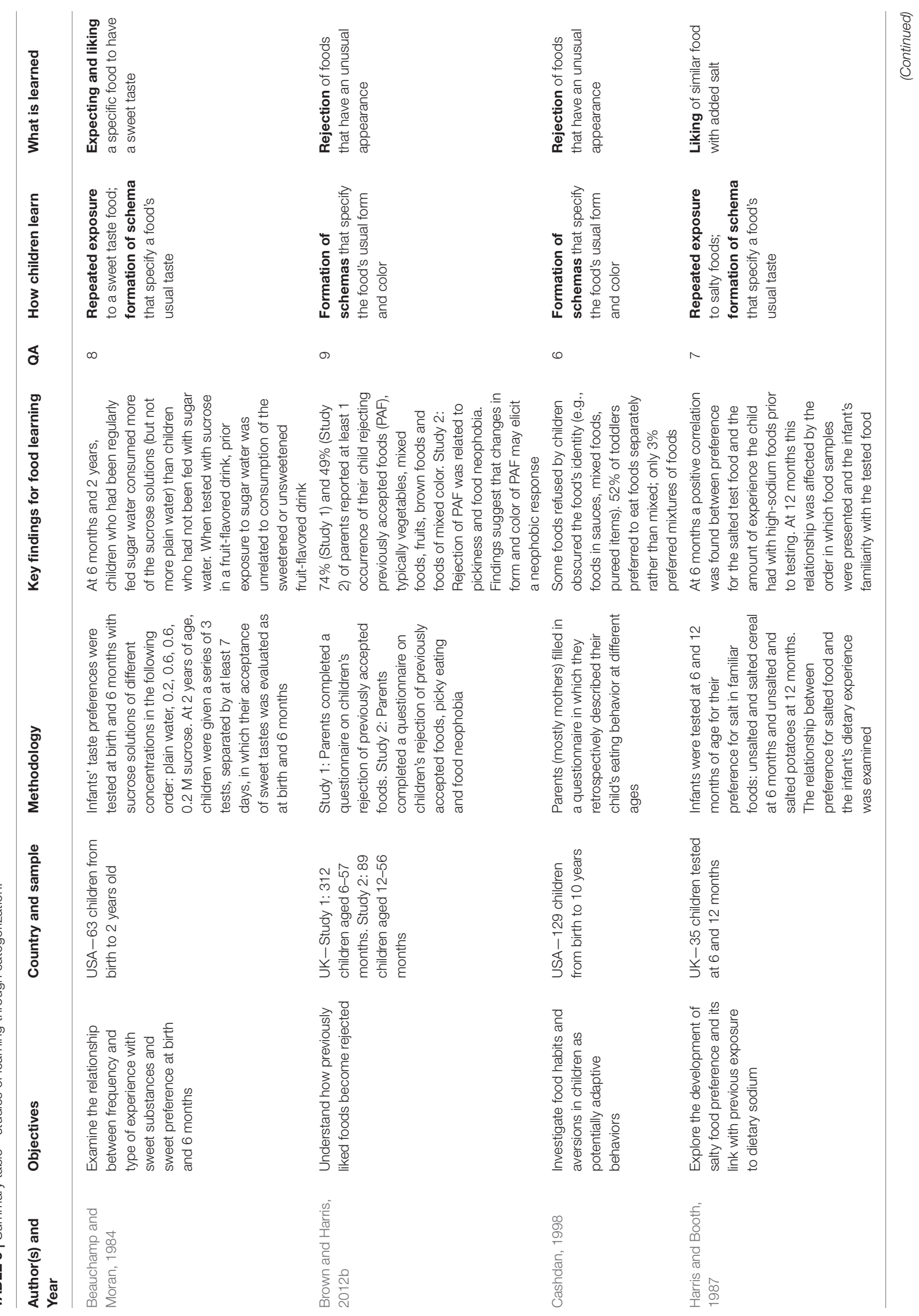




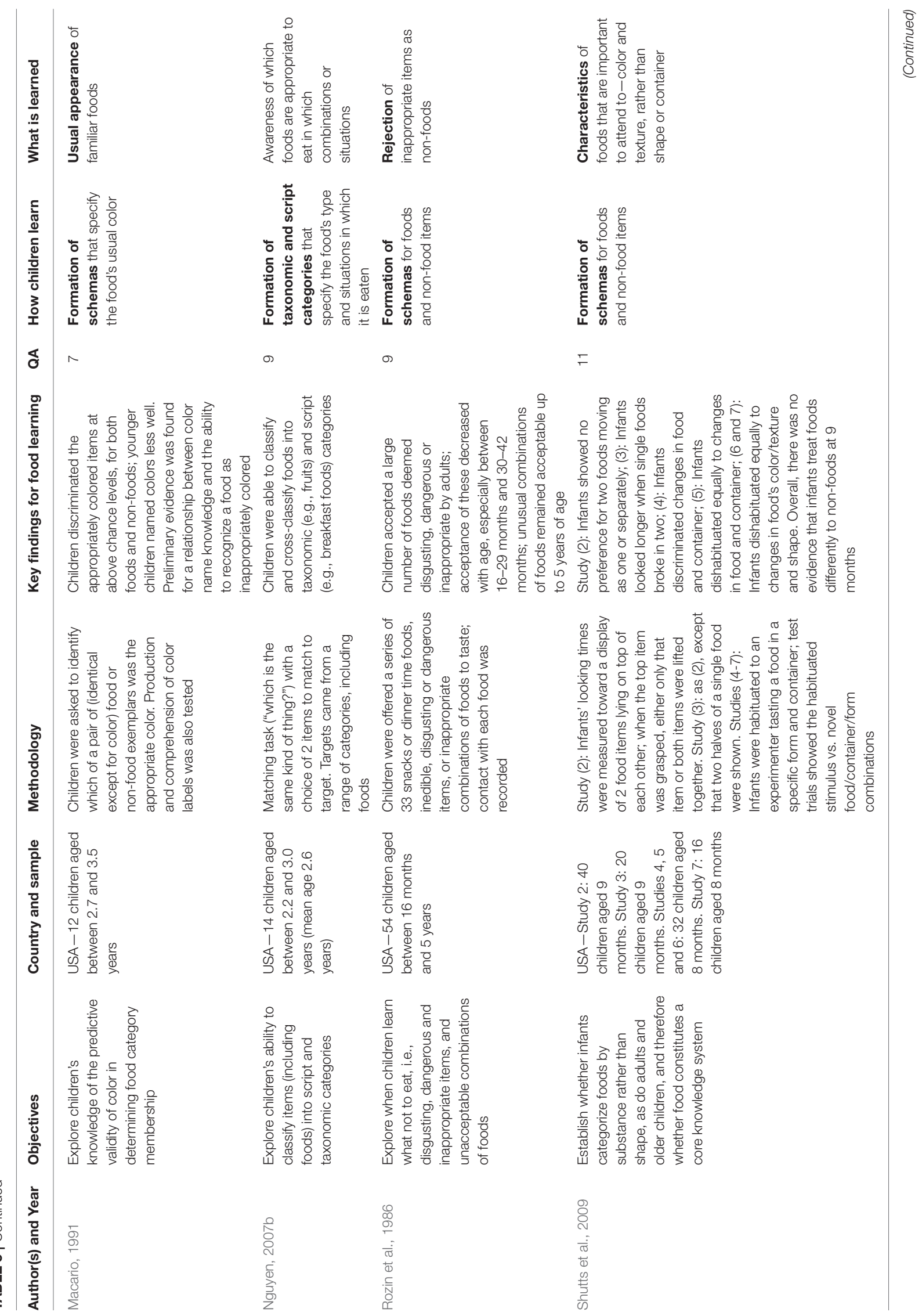




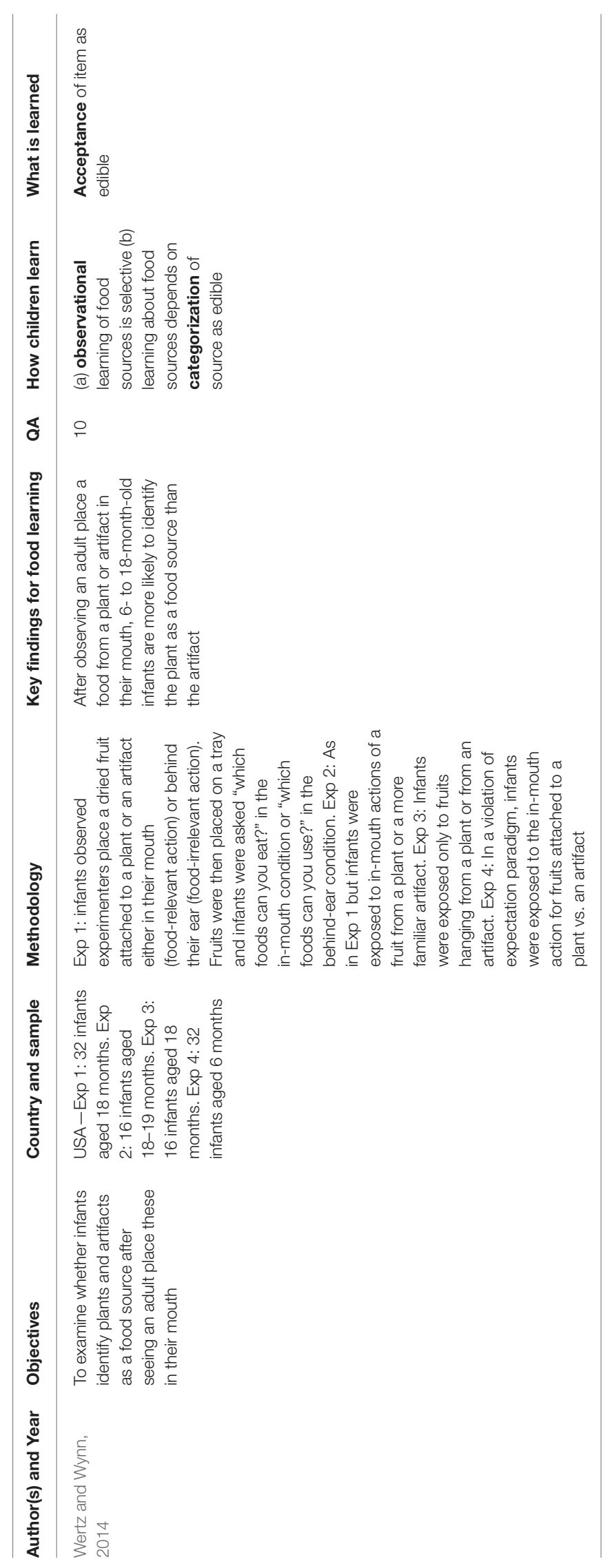




\section{SUMMARY OF LITERATURE}

The 48 papers that met the quality assessment criteria were grouped according to the learning process(es) they addressed: 24 papers described studies involving familiarization, 12 explored the role of associative learning, 17 reported studies of observational learning and 9 examined the role played by categorization. This fourteen papers investigated more than one learning process. In the following sections, we introduce each identified learning process, summarize the findings of the papers of relevance to it, and highlight gaps in knowledge remaining to be explored.

\section{Familiarization through Exposure}

Familiarization to a stimulus through repeated exposure can increase liking of it. Thus, familiarization with the taste of a previously disliked or unfamiliar food can lead to increased liking and intake. The powerful influence of familiarity begins at the very earliest stages of life, when infants ingest flavors while in utero and during milk feeding (Mennella et al., 2009; Nehring et al., 2015), and continues into adulthood (Zajonc, 1968). Here we focus on the effects of exposure to specific tastes or foods from the beginning of weaning to 36 months of age. There are several theoretical perspectives on the mechanism that underpins this effect. According to Zajonc, repeated presentation of a stimulus causes a shift in affect toward it. Thus, familiarized foods take on a more positive valence and are simply liked more. Kalat and Rozin (1973) alternatively offer a "learned safety hypothesis," according to which repeated exposure teaches us that ingestion of a food is not associated with negative consequences and, thereby, that it is safe to eat.

Twenty-four studies have explored the effects of repeated exposure to food in children between the time of weaning and 36 months. One article (Caton et al., 2014) reports a metaanalysis of 3 separate studies (Hausner et al., 2012; Caton et al., 2013; Remy et al., 2013). Findings originate from the UK, USA, Netherlands, Denmark, France, Ireland and Germany. The mean quality assessment score for these papers was 9.3 (range 7-11), indicating that research conducted in this area is generally of high quality. The 24 studies provided exposure in one of four ways: exposure to specific tastes or foods; exposure to a variety of food types; exposure to a variety of food textures; or exposure to a food's appearance.

\section{Exposure to Specific Tastes or Foods}

The literature confirms that the tastes infants are exposed to at an early age have long-lasting effects on their liking of specific tastes. Beauchamp and Moran (1984) investigated the effects of early exposure to water containing sugar on later acceptance of sweetened water. Infants who were repeatedly exposed to sugar water at 3 months of age showed increased acceptance of sugar water relative to plain water at 2 years of age compared to those who had never tasted it. Harris and Booth (1987) reported that, by 6 months of age most infants have a preference for salty foods, but the strength of this preference was related to the number of times the child had consumed salty foods during the previous week. Interestingly, 12-month-old infants showed no relationship between their preference for salty foods and their recent consumption of these. By this age infants preferred foods to be salty only if that food type usually contained added salt, suggesting that familiarity with specific food-flavor combinations becomes more important with age. Blossfeld et al. (2007a) also reported that exposure to specific tastes early in life is associated with later taste preferences. While sour tastes are generally rejected by infants and young children (Desor et al., 1975; Steiner, 1977), Blossfeld et al. found that some 18-month-old children accepted sour-tasting solutions, and that these children reportedly had higher intake of fruit post-weaning.

Repeated exposure has also been demonstrated to be effective in encouraging infants to consume more of a target food during the weaning period. Sullivan and Birch (1994) reported increased intake of an unfamiliar vegetable (peas or green beans) by 4 - to 6-month-old infants after 10 taste exposures to the vegetable. Forestell and Mennella (2007) confirmed that consumption of green beans by 4 - to 8 -month-olds tripled after 8 days of exposure, while Birch et al. (1998) demonstrated that a single exposure was sufficient to increase intake in infants of this age. Maier et al. (2007) showed that repeated exposure can also increase infants' intake of an initially disliked food. Eight exposures to a disliked vegetable were sufficient to increase intake in 7-month-olds, an effect that was sustained for at least 9 months in two-thirds of the children. More recently, Remy et al. (2013) found that 10 exposures to a new vegetable during weaning increased infants' intake of the food both in the short term and up to 6 months later.

Several studies have shown repeated exposure to a new food to increase intake in infants and toddlers beyond the weaning period. Bouhlal et al. (2014) found that exposing 2- to 3-yearold children to salsify 10 times increased intake of this vegetable, while de Wild et al. (2013) demonstrated that repeated tasting of an unfamiliar vegetable soup (endive) increased intake compared to baseline in children aged 2-5 years. The effects of repeated exposure can also be long-lasting at this age. Five to ten exposures to the taste of an unfamiliar vegetable have been shown to increase intake at 2 weeks (Caton et al., 2013, 2014) or even 6 months (Hausner et al., 2012) after the intervention. The survey study by Ahern et al. (2013) supports this body of evidence in demonstrating that repeated exposure leads to greater liking of vegetables.

\section{Exposure to a Variety of Foods}

Exposing an infant or young child to a variety of foods at a young age is effective in promoting liking and intake of both exposed foods and other new foods. Gerrish and Mennella (2001) found that exposure to a variety of foods enhanced acceptance of an unfamiliar food at weaning. In this study, 5-month-old infants consumed more of the target vegetable when they had previously been exposed to either the target vegetable or to a variety of vegetables other than the target food, compared to infants only exposed to potato. Infants in the "variety" condition also consumed more of an unfamiliar meat dish than infants in other conditions. The extent to which exposure to a variety of tastes promotes acceptance of unfamiliar foods may vary according to the specific foods 
exposed, however. Barends et al. (2013) recently reported that starting complementary feeding with exposure to a variety of vegetables increases acceptance and consumption of fruit and vegetables, while exposing infants to a variety of fruits at the start of weaning does not increase fruit consumption or vegetable acceptance.

Studies that have explored the consequences of exposing infants to a variety of foods suggest that the schedule used to introduce new foods is important. Maier et al. (2008) found that exposure to three different vegetables on a daily basis was more effective in increasing intake in 6-month-olds than alternating presentations so that the vegetables were each tasted once every 3 days. A follow-up study showed that, at 6 years of age, children who had been exposed to the high-variety intervention were more willing to taste new vegetables and liked and consumed more of these (Maier-Nöth et al., 2016). By manipulating the presentation of vegetables within meals and days, Mennella et al. (2008) demonstrated that both within-meal and betweenmeal variety enhance 6-month-olds' acceptance of a new (nonexposed) vegetable.

\section{Exposure to a Variety of Textures}

Lundy et al. (1998) compared the willingness of infants at the weaning and post-weaning stage (4-12 months) and infants in their second year (13-22 months) to accept foods of different textures. The older infants more readily accepted textured foods than younger infants, attributed to their greater experience with textured foods. Similarly, Blossfeld et al. (2007b) reported that 12month-old infants with prior experience of carrots in a variety of forms (tastes and textures) consumed more chopped carrots than infants who had not experienced such variety. These studies suggest that acceptance of textured foods may be supported by exposure to foods prepared to have different textures.

\section{Repeated Visual Exposure to Foods}

Repeated visual exposure has also been demonstrated to be effective in increasing children's liking of target foods. Birch et al. (1987) explored the effectiveness of repeatedly exposing children of 2-5 years to either the appearance or taste of novel fruits. They found that asking toddlers to look at foods repeatedly did not affect children's ratings of how much they liked the food's taste. However, children gave higher ratings when asked how much they liked the appearance of the foods they had looked at. As expected, repeated exposure to a fruit's taste was related to acceptance of the food. The authors concluded that to obtain positive changes in preferences, experience with a food must occur in a relevant modality.

More recently, Houston-Price et al. (2009) exposed infants aged 21-24 months to pictures of fruits and vegetables in a picture book every day for 2 weeks, after which children took part in a taste test. Repeated visual exposure increased children's willingness to taste a previously unfamiliar fruit, compared to a non-exposed unfamiliar fruit, suggesting that looking at foods can positively influence eating behavior. However, the same pattern was not shown for vegetables; looking at familiar vegetables decreased children's willingness to taste these, suggesting that the effects of visual exposure may depend on the food type and the child's prior familiarity with it. A larger follow-up study by Heath et al. (2014) showed that picturebook exposure can enhance toddlers' consumption of vegetables, however. In line with the findings of Houston-Price et al. (2009), the strongest effects were seen for previously unfamiliar vegetables. Weaker positive effects were also seen for familiar (liked and disliked) foods in this study, suggesting that earlier concerns about potential negative effects of visual exposure are unwarranted. This recent work suggests that prior visual exposure in the absence of any opportunities to taste the food can support toddlers in accepting new foods, although further empirical studies that corroborate these findings would be required for strong conclusions to be drawn.

\section{Familiarization-Summary of Results and Gaps in the Literature}

Familiarization via repeated exposure is an important means by which children learn about food during the weaning period and early childhood. Children learn to accept specific tastes through experience, and the effects of early familiarization appear to have long-term effects on consumption. For example, one intervention study has shown effects up to 5.5 years after the exposure was provided at the start of complementary feeding (Maier-Nöth et al., 2016), while an observational study has shown that preferences at 2 years of age correlated with preference at 20 years of age (Nicklaus et al., 2005). Repeated exposure to a variety of foods or food textures can also elicit a willingness to accept further new foods or textures into the child's diet. Finally, visual familiarity with foods may also support infants and toddlers in tasting unfamiliar foods.

The majority of studies yielded by our search involved infants younger than 12 months. While repeated exposure appears to be effective for children up to 36 months of age, further research is needed with children at the older end of our age range. A recent study suggests that repeated exposure becomes less effective as a means of increasing vegetable intake with age, at least within the weaning to 36 month age period; children older than 24 months showed less change in acceptance following exposure than younger infants in this study (Caton et al., 2014). This may be related to the neophobia often shown by children at this age (Dovey et al., 2008); it may be difficult to persuade a child who is very reluctant to taste new foods, and who might even refuse to eat previously-liked foods, to engage in repeated tastings of a new or disliked food. We return to this issue - and to the question of how early exposure leads to long-term changes in children's food preferences-in the Discussion section, when we consider the implications of the literature on all four learning strategies in relation to developmental changes in how children learn about food.

\section{Associative Learning}

Infants are born with a liking for sweet tastes and a tendency to reject bitter tastes (Steiner, 1979). They must therefore learn to like foods such as vegetables, which have bitter taste components. Such learning may be supported by associative learning (Brunstrom et al., 2005), an umbrella term for processes that support the formation of associations between two stimuli 
or between a stimulus and a behavior. In the context of learning about food, associations might be formed in several ways, including: (i) flavor-flavor learning (FFL), in which repeated pairing of a new or disliked food with a familiar and liked taste, such as sweetness, leads to acceptance of the food in the absence of the sweet taste; (ii) flavor-nutrient learning (FNL), in which new foods are paired with high-energy dense ingredients, such as fat or maltodextrin, to enhance post-ingestive satiety signals, exploiting children's natural preference for energy-dense foods; (iii) contamination (association of a new food with a disliked food); or (iv) reward (e.g., association of a food with praise).

Twelve studies have explored the role of associative learning in our target age range. Findings originate from the UK, USA, Australia, France and Denmark. The mean quality assessment score for these papers was 9.4 (range 7-11), indicating that the research in this area was generally of high quality.

Early studies of FFL and FNL suggested that children's liking and intake of target foods was influenced by their association with liked tastes or satiety signals. Johnson et al. (1991) demonstrated a preference for a flavor associated with higher energy density (FNL) in children aged 2-5 years. Coyle et al. (2000) demonstrated that olfactory associative conditioning could be used to increase intake of water in 6-month-old infants (FFL). During three feeds, infants were exposed to a scented disc placed around the top of a bottle containing their regular, liked formula milk. Pre-intervention water consumption was measured without the scented disc, and post-intervention water consumption was measured either without the scented disc, with a disc with the familiar scent, or with a disc with an unfamiliar scent. Post-intervention water intake was greatest when infants were exposed to the familiar scent, suggesting that they had learned to like the scent through its association with milk. These findings suggest that olfactory conditioning might be used to support infants' intake of less palatable drinks when these are first introduced.

However, recent studies comparing the effectiveness of associative learning manipulations (in which exposure to the target occurs in association with a liked flavor or satiety) with exposure alone typically find no advantage to manipulations involving conditioning. Forestell and Mennella (2007) investigated whether 6-month-olds' acceptance of a (bitter) vegetable was enhanced when they were offered a (sweet) fruit purée immediately after each taste of the vegetable. Infants' intake of green beans was no greater among infants who tasted peach purée after the beans than in infants who tasted only the beans, suggesting that repeated exposure to the vegetable was sufficient to increase intake. Four recent investigations have directly compared the effectiveness of FFL, FNL and repeated exposure in infants aged between 6 and 36 months (Hausner et al., 2012; Caton et al., 2013, 2014; Remy et al., 2013). In these studies, infants were offered a taste of an unfamiliar vegetable (artichoke) either in sweetened form (FFL), with added oil to boost the food's energy content (FNL), or without any additive (repeated exposure). The addition of sweetener or oil conferred no advantage over repeated exposure in each case; post-intervention intake of artichoke was actually higher in the repeated exposure condition than in either associative learning condition in all four studies.

These studies suggest that the addition of a sweet taste or energy is not necessary to promote the consumption of vegetables in children aged between 6 and 36 months. Indeed, recent evidence suggests that when children are given ad-libitum access to foods, their natural preference for energy-dense foods does not necessarily lead to increased intake of these. For example, de Wild et al. (2013) found no difference between children's intake of an unfamiliar vegetable soup with or without added oil, even though the toddlers who participated in their study reported stronger liking for the soup with greater energy density. Similarly, Bouhlal et al. (2014) showed that exposing children of 2-3 years to salsify on 10 occasions was sufficient to increase intake of this vegetable, and that adding salt or nutmeg added no benefit. The authors conclude that repeated exposure is the simplest route to increase vegetable intake in toddlers.

Other forms of associative learning, such as the pairing of a food with parental reward or pressure to eat, have been shown to impact on preschoolers' and older children's willingness to consume the food. For example, Vereecken et al. (2004) showed that parental verbal praise is positively related to the vegetable consumption of children aged between 2.5 and 7 years, while Gregory et al. (2010) found that parental pressure to eat was related to lower interest in eating among 2- to 4-year-old children, suggesting the formation of positive and negative associations respectively. Evidence that younger 18- to 26-month-old infants are also influenced by the formation of negative associations comes from a study by Brown and Harris (2012a). When a new food was presented alongside a disliked food, and the two foods touched, the disliked food acted as a "contaminant," reducing infants' willingness to consume the new food.

\section{Associative Learning-Summary of Results and Gaps in the Literature}

In summary, while olfactory associative learning might be useful in helping infants to accept otherwise rejected liquids, such as water, the literature is consistent in demonstrating that conditioning techniques such as FFL or FNL provide no advantage over repeated exposure in shaping the food preferences of infants in the weaning and toddler periods. Hence, repeated exposure is preferred as a way to shape food preferences. There is a dearth of evidence on the role played by other forms of associative learning in the age group of interest, however, although studies with older toddlers and school-aged children indicate that positive and negative associations may be formed with foods. Further research is therefore needed to identify whether infants form positive and negative associations on the basis of the physical and social environments in which foods are offered.

\section{Observational Learning}

A third body of research concerns the role played by observational learning. Observational learning (also termed "social learning" or "modeling") involves the observation and imitation of others' behavior (Bandura, 1977). Infants have a 
natural tendency to imitate, moderated by the emotional quality of the relationship between the observer and model. Parents are therefore highly influential role models, shaping a range of behaviors in their child, including eating behaviors.

From the start of weaning, infants' mealtimes increasingly take place in a family context. This might affect the child's eating behavior in two key ways. First, eating is "socially facilitated" (Clayton, 1978); if others are eating, we are also more likely to eat, and we are quicker to accept new foods (Visalberghi and Addessi, 2000). Second, family mealtimes expose children to the eating behaviors of parents and siblings, who they may try to imitate. Observing others eating a food increases the likelihood that children will want to taste the same food. Thus, social facilitation and observational learning play an important role in determining children's food preferences and eating behavior; they may also teach the child which foods are safe to eat, how they should be eaten, and how much of them it is appropriate to eat.

The search identified 17 studies investigating the role of observational learning, conducted in the US, UK, Australia, Canada, Denmark, France and Belgium. The mean quality assessment for these articles was 9.2 (range 7-11), demonstrating the generally high quality of the research on this topic. Three themes were identified among these papers: (i) the immediate impact of models on children's eating behavior, and the factors that determine the model's influence; (ii) the longerterm consequences of modeling on the development of food preferences; and (iii) similarities between the food preferences and eating behavior of children and family members.

\section{Effect of Modeling on Immediate Food Acceptance}

Several studies demonstrate that children under 3 years of age are influenced by seeing others eat. Lumeng and Hillman (2007) showed that the mere presence of others induces eating in young children (between 2.5 and 6.5 years), as it does in adults. When children were given an extended period in which to snack, the number of children in the group predicted the amount consumed. Edelson et al. (2016) studied the prompts parents use to encourage their children aged 12-36 months to eat specific foods at mealtimes. The prompts observed included pressure to eat, use of another food or a non-food item as a reward, reasoning with the child, and modeling eating the food; the authors found the most successful prompt across food types to be modeling. Harper and Sanders (1975) and Addessi et al. (2005) both found that intake of a new food was greater when children observed a model eating the food than when the child was simply offered the food to eat. It also seems to be important that the food the model is eating looks similar to that offered to the child. Addessi et al. reported that the 2- to 5-year-old children in their study were more likely to accept a food that was the same color as that eaten by a model.

Other work has explored the ages at which children show observational learning of eating behavior. Harper and Sanders (1975) showed that children as young as 14 months old are more likely to eat an unfamiliar food if they see an adult eating it; girls were more strongly influenced by the adult's eating behavior than boys. However, not all adult models are equally effective; in the same study, children between 14 and 20 months old were more likely to accept a food offered but not eaten by the mother than a food offered but not eaten by a visitor. From 24 months of age, parents (Pliner and Pelchat, 1986) act as effective models. Peer modeling is a particularly strong motivator at 3 years of age, when it can arouse a desire to taste non-preferred foods as well as new foods, and to enhance reported liking of these (Birch, 1980). The same study found that peers had less influence over the food choices of 4-year-olds. However, Addessi et al. (2005) reported that peers had no influence over whether children aged between 24 and 45 months old would accept a food eaten by an adult model, suggesting that adults may still have the greater sway over children at this age.

Two further studies have explored the contextual factors that influence social learning of eating behavior. Hamlin and Wynn (2012) found that 15- to 16-month-old infants showed observational learning of the food preferences of puppets if the puppet had not been seen before or had been seen to display prosocial behavior, but not if the puppet had displayed antisocial behavior. Wertz and Wynn (2014) report a series of studies in which infants of 6 and 18 months were more likely to identify items as foods if the source of the food was a plant, rather than an artefact, and when the item was placed into a model's mouth, rather than behind their ear. These studies demonstrate that observational learning about foods is selective, and dependent on infants' prior experiences of where foods come from, how they are acted upon, and whether the model is desirable to imitate.

\section{Longer-Term Impact of Modeling Healthy Eating}

The impact of observational learning on longer-term acceptance of a food has also been investigated. Gregory et al. (2010) found that maternal modeling of healthy eating for 3-year-old children was positively correlated with reports of the child's interest in food and negatively correlated with measures of food fussiness and food responsiveness when children were 4 years of age. Gregory et al. also found that children who were reported to enjoy the experience of shared family mealtimes were more positive about trying new foods in a non-modeling context. Other work has revealed links between maternal modeling of healthy eating and consumption of fruits and vegetables by children aged older than 2 years. Using a multifactorial approach, mothers' consumption of fruit and vegetables was found to be a stronger predictor of children's fruit and vegetable consumption than her educational level (a proxy for socio-economic status) and indices of parental feeding practices, such as permissiveness and use of rewards (Vereecken et al., 2004; Wardle et al., 2005). The survey by Ahern et al. (2013) also supports parental modeling as a determinant of children's liking of vegetables.

\section{Similarity between the Food Preferences of Children and Family Members}

Several studies have shown similarities in the food preferences of children aged 24-36 months of age and their family members, and Pliner and Pelchat (1986) found that these relationships remain stable until at least 6 years of age. In a recent survey of 550 families of young children, parents' fruit and vegetable consumption was the strongest predictor of children's fruit and vegetable intake (Wardle and Cooke, 2008); others have similarly 
reported strong correlations between measures of food intake among family members (e.g., Laskarzewski et al., 1980; but see Faith, 2005, for a review of studies finding weaker correlations). Work by Ashman et al. (2014) found an association between a mother's post-natal diet (but not her diet during pregnancy) and the variety of fruit and vegetables in the child's diet at 2 and 3 years of age.

There is some discrepancy in the literature about which family members' eating preferences are most strongly associated with those of their children. According to Skinner et al. (2002), the mother's food likes and dislikes are most strongly associated; they shape the child's food preferences at 2 years of age and continue to do so until the child is 8 years old. However, Skinner et al. (1998) found strong correspondences between the child's food preferences and those of both parents. Pliner and Pelchat (1986) reported that children's food preferences were more similar to those of their own families than to those of members of pseudo families (families from the same subcultural group with a child in the target age range). This finding was especially pronounced for siblings, and children's food preferences were more similar to those of siblings, both real and pseudo (i.e., other children), than to those of their parents.

McGowan et al. (2012) investigated the environmental and individual predictors of young children's intake of core and noncore foods (foods that do not contribute to the nutritional needs of children). Parental intake was the only factor shown to predict children's intake across all types of foods (fruits, vegetables, and non-core foods), while feeding style, children's preferences and availability were predictors for some food types but not others.

\section{Observational Learning-Summary of Results and Gaps in the Literature}

The experimental studies reviewed demonstrate that observational learning has an impact on the eating behavior of children in our age range. However, children are not passive imitators of those around them; they draw on prior experience to select which models to learn from. In the longer term, modeling of healthy eating predicts lower food fussiness and is a stronger predictor of children's fruit and vegetable consumption than parenting style or socio-economic status. In addition, correlational studies show that children's food repertoires are similar to those of their families until at least 8 years of age. However, while similarity between the food preferences of children and the people in their immediate environment may result from observational learning of others' food choices, it may also reflect the availability of the foods eaten by those in the child's immediate environment, and/or the child's exposure to these foods. It is difficult then to disentangle the effects of observational learning from the effects of exposure in studies reporting correlations between the food choices of children and their family members. Indeed, the literature suggests that the sharing of food likes and dislikes by family members is not solely due to observational learning by the child; the cultural context in which the family eats and the availability of foods also play a role, as indicated by the shared preferences of children from similar socio-cultural backgrounds.
In contrast to the effects of familiarization on food preferences, which are evident from the beginning of weaning or even earlier, observational learning from adult models has been shown to occur from 14 months of age, while peer modeling has been shown to be effective from about 2 years of age. Whether the later appearance of observational learning is due to genuine changes in the learning strategies employed in the second year or reflects the dearth of research in younger infants remains to be established. Further experimental work is needed to establish the effect of role models on younger infants' food choices, and to corroborate the preliminary evidence that suggests that children change in their sensitivity to different role models as they grow older.

\section{Categorization}

Humans spontaneously organize objects and events into categories in order to make sense of the world (Rakison and Oakes, 2003) and store organized bodies of knowledge about the characteristics, functions and properties of these categories as schemas (or, in the case of event schemas, as scripts). Schemas allow us to generalize our existing knowledge to new members of a category, enabling us to know how to behave toward these immediately, rather than having to learn about each new stimulus we encounter (Piaget, 1953). Children begin to spontaneously categorize objects in their environment within the first half year of life (Mareschal and Quinn, 2001; Rakison and Oakes, 2003) and use scripts to organize their knowledge of events by the second year (Fivush et al., 1987).

Recent reviews suggest that the categorization of the food domain plays an important role in shaping children's food preferences and eating behavior, particularly their reactions to unfamiliar foods (Pliner, 2008; Aldridge et al., 2009). Foods lend themselves to multiple forms of categorization (Ross and Murphy, 1999). The child must first distinguish between foods and non-foods to make appropriate selections of things to eat (Fallon and Rozin, 1983; Rozin, 1990). The food domain is then organized hierarchically into taxonomic categories, such that superordinate categories (e.g., fruits) contain subcategories (e.g., berries, citrus fruits), which in turn comprise further subcategories (e.g., cranberries, tangerines). Foods also belong to thematic categories of items that commonly co-occur but share no properties in common (e.g., chips and ketchup), and script categories of items that play similar roles in an event schema (e.g., breakfast foods) (Nguyen and Murphy, 2003). Nguyen (2008) proposes that we also group foods into evaluative categories, based on an assessment of a food as healthy or unhealthy, good or harmful, delicious or disgusting. A food's evaluative category, alongside its status as familiar or unfamiliar, determines whether it is accepted or avoided. Recent studies have shown that children use taxonomic, script and evaluative categories to represent the food domain from 3 to 4 years of age, and can simultaneously cross-classify foods as belonging to more than one category by age 4 Nguyen and Murphy, 2003; Nguyen, 2007a,b, 2008).

The review identified 7 articles that directly explored children's categorization of the food domain, or how this is reflected in their reactions to new foods, in the period from weaning to 36 months. Two further articles on the effects of 
familiarization also provide some insight into the role played by categorization. The mean quality assessment score for these articles was 8.3 (range 6-11), suggesting some variability in the quality of these articles. The papers address two main questions: (1) What do young children accept as edible items and, relatedly, why are foods that were previously accepted sometimes rejected at a later stage? (2) How are foods categorized by young children?

\section{What Do Young Children Accept As Food?}

Previous work has shown that children progress gradually from an initially broad acceptance of many items as potential foods to a narrower, adult-like awareness of what is edible (Rozin and Fallon, 1980; Fallon et al., 1984). The different ages at which children reject unpleasant, dangerous, disgusting and inappropriate items as foods suggest that the development of the non-food category is an incremental process (Fallon et al., 1984; Rozin et al., 1985; Rozin and Fallon, 1987). Rozin et al. (1986) explored this developmental trend in children aged between 16 and 60 months. The youngest group (aged 16-29 months) readily tasted items considered dangerous, disgusting, inappropriate or unacceptable combinations by adults, and acceptance of inappropriate items and unacceptable combinations remained surprisingly high in children older than 30 months. Rozin et al. (1986) suggest that such behaviors reflect children's ignorance of the properties of non-food items that render these inedible; the authors also raise the possibility that young children lack an adult-like categorical distinction between foods and non-foods.

Two studies have investigated the factors that underlie young children's rejection of foods. Cashdan (1998; see also Cashdan, 1994) asked parents to retrospectively complete a questionnaire about their child's food receptivity during early childhood. Rejected foods tended to be those that obscured the identity of component ingredients (e.g., sauce-covered or mixed foods). A subgroup of parents was asked whether their child preferred mixed or individual foods during toddlerhood; parents reported a clear preference for non-mixed foods. Brown and Harris (2012b) investigated the frequency with which children aged between 6 months and 4.5 years reject previously-accepted foods. The majority of parents reported that their child had rejected at least one food they had previously enjoyed eating. The most frequently rejected foods were vegetables and food combinations, and foods that were brown or multi-colored. The authors suggest that such foods may be difficult for children to recognize or classify as a specific food; while the child might have enjoyed a food in the past, changes in its visual appearance might lead it to be rejected as a new or unfamiliar food. Together, the studies by Cashdan (1998) and Brown and Harris (2012a,b) suggest that children prefer foods they are able to recognize as belonging to a particular food type.

Unfamiliar combinations of flavors may also hinder acceptance. Beauchamp and Moran (1984) found that, while prior exposure to sugar water increased infants' consumption of sugared water, it had no impact on intake of sweetened fruit-flavored drinks. Harris and Booth (1987) also reported that 12-month-old infants preferred foods to be salty only when that food type usually contained added salt. Thus, both studies suggest that certain tastes are accepted only in recognized combinations.

\section{Categorization of the Food Domain}

Recent work suggests that 2-year-old children categorize foods and non-foods in a similar way to adults. Nguyen (2007b) showed that children of this age are able to cross-classify food and non-food objects on the basis of the item's taxonomic or script category. When asked to select which of two pictures was "the same kind of thing" as a third, target picture, items from the target's taxonomic or script category were selected at above chance levels. Although responses toward food and non-food stimuli were not analyzed separately, the results are suggestive that the food domain may be organized in a coherent manner by 2 years of age.

Some have suggested that infants' knowledge of the food domain might be supported by a "core knowledge" system, which directs our attention to the relevant characteristics of items to help us distinguish category members from non-members (Spelke and Kinzler, 2007). Shutts et al. (2009) explored whether, like adults, older children and monkeys, 8- and 9-monthold infants categorize food and non-food objects by substance (conveyed by color, texture and smell) or by shape (the primary factor in categorization of non-foods). A series of rigorouslycontrolled looking-time studies found no evidence that infants respond differently to food and non-food objects. Shutts et al. concluded that, rather than possessing innate core knowledge about food, children must learn the relevance of color and texture to food categorization through their experiences in later infancy.

By the late preschool years, however, children base their inferences about foods and non-foods on relevant properties, such as color, texture and smell (Macario, 1991; Lavin and Hall, 2001). For example, when Macario (1991) introduced a novel object as a toy and asked, "Which one is like this one to play with?" 3- and 4-year-old children generalized the item's properties to an object that matched in shape. When the same object was introduced as a food, and children were asked "Which one tastes like this one?" an object of the same color was selected. In a second study, 2- and 3-year-old children matched foods to their appropriate colors, suggesting that color is a relevant property for categorizing foods by 2 years of age.

\section{Categorization-Summary of Results and Gaps in the Literature}

During the first year of life, infants do not distinguish foods from non-foods in either the physical characteristics ascribed to food vs. non-food objects or the restrictions they place on what is considered edible. Children's willingness to consume inappropriate items shows that confusion over membership of the food domain continues well beyond toddlerhood. This is surprising considering that toddlers are able to classify foods according to their taxonomic or script categories by 2 years of age. Children's acceptance of non-food items as foods may therefore reflect their lack of experience with these items. Little is known about how children come to categorize foods in this period except that, by 2 years of age, a food's color is considered an invariant aspect of its identity. The ability to recognize a food by 
its shape and color is important to toddlers, who prefer foods to be presented separately rather than combined with other foods or hidden in sauce, and who reject foods whose appearance differs to a familiar preparation.

Many questions remain about the structure of children's food categories and how these relate to their preferences. Research is needed to establish how children develop adult-like food categories, and how these are shaped by the child's sensory experiences of foods and/or the behavior of people around them. Little is known about the role played by the names used for food categories and characteristics (i.e., food labels), although recent work has shown that the ability to label a food's flavor is related to children's memory of the flavor (Lumeng et al., 2005), suggesting that knowing the name of a food might impact on its familiarity, and hence on liking. Another remaining question concerns how young children represent foods with conflicting evaluative categories (e.g., delicious but fattening, or disgusting but nutritious). Answering this question would further our understanding of the factors underpinning children's food preferences (Nguyen, 2008).

\section{DISCUSSION}

This article is the first systematic review of the literature on how children learn about food between weaning and 3 years of age. The review clarifies the role played by known learning processes-familiarization, associative learning, observational learning and categorization-in the development of children's understanding of food.

Although attention to the development of eating habits is increasing among researchers, the number of empirical articles relevant to this topic in this age range up to 2016 is only 48 . The literature is therefore surprisingly limited in its scope. The large majority of the studies identified was conducted in USA or Europe, with a small number of studies from Australia and none from other parts of the world. As obesity is increasing in many parts of the globe, investigations into children's learning about foods in other regions and cultures are needed. A further limitation of the literature to date is its almost exclusive focus on children's consumption of fruit and vegetables. Other wholesome foods, such as fish and whole-grain cereals, are also underconsumed, but no study involving children less than 3 years has used these as target foods. Perhaps most importantly, most studies have established only short-term effects of interventions on children's knowledge or behaviors toward foods, when longerterm influences are of primary importance. We also acknowledge that our strict inclusion/exclusion criteria may have impacted on the pool of studies that were summarized, and therefore on the conclusions that were drawn. For example, in an effort to focus the review on the learning mechanisms employed by children outside the context of adverse environmental or biological conditions, our search terms excluded studies of food-related behavior in low income groups and atypical populations; we found that studies of food-related learning in "low income" groups often highlight issues of food insufficiency ("food insecurity"), which we considered beyond the remit of the review. It is possible, therefore, that the criteria adopted limit the generalizability of the conclusions to certain sub-groups of children. At the same time, around a third of the studies summarized in the review involved a participant sample that exceeded the upper limit of our target age range. In several of these articles no distinction was made between the behaviors of children younger and older than 36 months, which may have resulted in the inadvertent drawing of conclusions that are inappropriate for our target age group.

The literature search revealed an imbalance in the size of the literature exploring different forms of learning. The majority of studies have investigated the effects of familiarization $(N=23)$; these provide a robust demonstration of the role of repeated exposure. From the start of the weaning period, repeated exposure to the taste of foods helps infants accept these into their diets (Birch et al., 1987 and 20 other papers, see Table 2). At the same age, regularly offering infants a variety of foods enhances their willingness to try other new foods, facilitating the acceptance of a wider variety of foods into the diet (Gerrish and Mennella, 2001 and 4 other papers, see Table 2). By the second year, exposure to a variety of textures enhances acceptance of the more complex textures that are typical of wholesome foods (Blossfeld et al., 2007b). Repeated visual exposure to unfamiliar foods in children of 20 months and older (Houston-Price et al., 2009; Heath et al., 2014) can also support acceptance of these foods.

Fewer papers report findings relating to observational learning (17), associative learning (12) and categorization (9) in infancy, and there remain significant gaps in our understanding of the role of these processes. Within the associative learning domain, there is a paucity of literature on the effects of associations formed with the physical and social environment in which infants eat. Though beyond the scope of this review, studies concerning the impact of parental feeding style and parental feeding practices such as expressed through parental praise, encouragement and pressure to eat, may extend our understanding of how infants and toddlers learn about food. Similarly, how do factors associated with the eating environment (such as the atmosphere at family mealtimes or the presentation of liked and disliked foods together on a plate) influence children's willingness to eat?

Studies of conditioning forms of associative learning have shown that the addition of a sweet taste (flavor-flavor learning, FFL) or energy (flavor-nutrient learning, FNL) confers no advantage over repeated exposure in increasing consumption of the food in the weaning or toddler stages (Hausner et al., 2012; Caton et al., 2013, 2014; de Wild et al., 2013; Remy et al., 2013; Bouhlal et al., 2014). These findings further highlight the powerful role of taste exposure in isolation during this period.

FNL is assumed to be mediated by a decreasing state of hunger (Mobini et al., 2007); children are typically hungry at the start of feeding and less hungry or satiated at the end. In repeated exposure conditions children are often allowed to eat to satiety or close to satiety. As a consequence additional energy density may not increase the reward experienced, explaining the lack of advantage of FNL over repeated exposure.

A further factor that might explain the lack of benefit of FFL or FNL over repeated exposure relates to the number of 
exposures provided, which is typically 10 in the interventions that compare different exposure regimes. Given that 8-10 exposures are sufficient to induce full acceptance of a food at the start of complementary feeding (Maier et al., 2007), there is little scope for any additional benefit of FFL or FNL when this number of exposures is provided, and differences between treatments would not be expected. However, there are practical reasons for exploring whether, when fewer exposures are provided, FFL or FNL might be beneficial, as mothers are reluctant to provide as many as 10 exposures to a disliked food in practice (Maier et al., 2007). Future research might explore whether FFL increases acceptance of a novel or initially disliked food at the very first encounter, for example.

The literature relating to observational learning shows that, by the second year of life, infants pay attention to the foods eaten by their parents, peers and other role models; they are more willing to taste and accept into their diets the foods they have seen others eating (Harper and Sanders, 1975 and 16 other papers, see Table 2). However, questions remain about the types of role model infants are most likely to imitate in the early stages of developing food preferences, and whether the effectiveness of these changes with age. Moreover, research is needed to establish the extent to which infants' food preferences result directly from social learning vs. from the shared availability of specific foods within a household or cultural group. While a large number of studies demonstrate a relationship between the foods that a child observes being eaten as an infant or toddler and those that are an accepted component of their diets later in life, the nature of this relationship is complex. Is it the child's early observational experiences that cement a food as acceptable in the longer term, or does this require ongoing experiences of observing others eat the food at mealtimes? Given the stability of the young child's eating environment and companions, the effects of social learning are likely to be cumulative in shaping the child's diet over many years. Moreover, it is possible that such effects are due not to the child's modeling of their parents' or peers' food choices but to the child's repeated exposure to the same foods eaten by their family members. In the home environment, exposure and observation are inextricably linked; longitudinal studies that manipulate these factors independently would be required to establish which is responsible for the strong correlation between the child's early eating environment and eating preferences in adulthood.

Further work is also needed to establish how early experiences with foods impact on children's developing knowledge of food categories, and how this supports food choice and intake. The literature in this area is small, but the papers reviewed indicate that, by the third year, children are aware of the circumstances in which foods should be eaten and which foods should be eaten together (Rozin et al., 1986; Macario, 1991; Nguyen, 2007b). They also suggest that young children are hesitant to accept foods they are unable to recognize from previous encounters (Cashdan, 1998; Brown and Harris, 2012b). Aldridge et al. (2009) recently argued that the neophobia children display at 2 years of age may be related to their uncertainty about how to categorize unfamiliar foods. Children must make assumptions about new foods based on their similarity in appearance, name or category to familiar foods; as a result, the child's attitude toward a new food might reflect their past positive or negative experiences with similar foods. Pliner (2008) suggests that, rather than being unable to categorize unfamiliar foods, early experiences with unpalatable new foods lead children to establish a category of novel foods that includes characteristic qualities such as "tastes unpleasant" and "may be dangerous to eat," setting up a strong bias to avoid new foods. Further research is required to test these hypotheses. Is consumption of a food increased if infants are supported in recognizing a food or if similarities between a new and a liked food are highlighted? Can a positive (rather than negative) category of novel foods be promoted from the outset by providing infants with a wide variety of tasty foods from the onset of weaning?

With the exception of studies that compare the effects of conditioning techniques with repeated exposure, the literature has largely ignored questions about the relative usefulness of different learning strategies, or how the effectiveness of these strategies changes with age. Table 6 provides an overview of the ages at which each learning mechanism has been shown to be employed by infants. With the exception of associative learning, each strategy has been shown to play a role in young children's food-related behavior within each of the defined age ranges from 4 to 36 months. Having said that, there are notable differences between what children are learning through each strategy at each age, which may reflect developmental changes in how children learn, as well as in what they are learning about (Snow and McGaha, 2003). It is important to note, however, that the gaps in Table 6 indicate an absence of evidence, rather than evidence of absence. Thus, Table 6 highlights that the 8to 24-month age group has been relatively little explored in terms of how they learn about food; most studies have involved infants in the early weaning period or toddlers older than 2 years. Future work should explore whether these missing cells in the table are merely gaps in our knowledge, soon to be filled in, or genuine indications of sensitive periods, in which one type of learning takes precedence over others. We also know little about how children manage conflicting sources of evidence about foods-e.g., when they observe someone eating a novel food that looks like something they have categorized as disgusting, in the context of a liked odor. Do children attend to a single source of information in their response to the food-and if so, does observational, associative or categorical learning win out-or is their behavior based on a weighted combination of the different factors at play?

We cannot be certain that the literature on which this review is based has uncovered all pertinent learning mechanisms. Goswami (2008a) identified four basic ways in which young children learn: (i) learning by imitation (analogous to our "observational learning" theme); (ii) learning by analogy (finding correspondences between events, situations or domains of knowledge in order to transfer knowledge from one to another), a formulation that overlaps with our conceptualization of "categorization"; (iii) statistical learning (detection of regularities in sensory input over time). Insofar as repeated exposure teaches that a food is safe to eat through the lack of aversive consequences following each encounter (Kalat and Rozin, 1973), 
TABLE 6 | Summary of what, how and when infants (weaning to 3 years) learn about food.

\begin{tabular}{|c|c|c|c|c|c|c|}
\hline \multirow{2}{*}{$\begin{array}{l}\text { What does the child learn? } \\
\text { Willingness to try: }\end{array}$} & \multirow[t]{2}{*}{$\begin{array}{l}\text { What are the learning } \\
\text { mechanisms? }\end{array}$} & \multicolumn{5}{|c|}{ At what age (months)? } \\
\hline & & $4-8$ & 8- 12 & $12-18$ & $18-24$ & $24-36$ \\
\hline \multirow{2}{*}{ a new food } & repeated exposure (visual) & & & & 2 & \\
\hline & observational learning & & & 2 & 2 & 3 \\
\hline \multicolumn{7}{|l|}{ Acceptance of: } \\
\hline \multirow{5}{*}{ a specific food } & repeated exposure (taste) & 11 & 1 & 2 & 1 & 4 \\
\hline & repeated exposure (variety) & 3 & & & & \\
\hline & repeated exposure (visual) & & & & 1 & \\
\hline & associative learning & 2 & & & & 2 \\
\hline & observational learning & & & 1 & & 5 \\
\hline \multirow{2}{*}{ a disliked food } & repeated exposure (taste) & 1 & & & & \\
\hline & observational learning & & & & & 1 \\
\hline a new complex texture & repeated exposure (variety) & & 1 & 1 & 1 & \\
\hline \multirow{3}{*}{ a same category food } & repeated exposure (taste) & 2 & & & & \\
\hline & repeated exposure (variety) & 2 & 1 & & & \\
\hline & observational learning & 1 & 1 & & & 1 \\
\hline a different category food & repeated exposure (variety) & 1 & & & & \\
\hline \multicolumn{7}{|l|}{ Liking of: } \\
\hline \multirow{2}{*}{ the appearance of a food } & repeated exposure (taste) & & & & & 1 \\
\hline & repeated exposure (visual) & & & & 1 & 1 \\
\hline the texture of a food & repeated exposure (variety) & & & 1 & 1 & \\
\hline \multirow{4}{*}{ the taste of a food } & repeated exposure (taste) & 3 & & & & 1 \\
\hline & repeated exposure (variety) & 1 & & & & \\
\hline & observational learning & 1 & 1 & & & 3 \\
\hline & associative learning & 1 & & & & 2 \\
\hline \multirow{2}{*}{ a disliked food } & repeated exposure (taste) & 1 & & & & \\
\hline & observational learning & & & & & 1 \\
\hline \multirow{2}{*}{ eating in general } & associative learning & & & & & 1 \\
\hline & observational learning & & & & & 2 \\
\hline \multicolumn{7}{|l|}{ Rejection of: } \\
\hline a familiar food & repeated exposure (visual) & & & & 1 & \\
\hline a liked food & associative learning & & & & 1 & \\
\hline food based on appearance & categorization & 1 & 1 & 1 & 1 & 1 \\
\hline inappropriate items as non-foods & categorization & & & & 1 & 1 \\
\hline \multicolumn{7}{|l|}{ Understanding about food \& eating: } \\
\hline \multirow{2}{*}{ appropriate sources of foods } & observational learning & 1 & & 1 & & \\
\hline & categorization & 1 & & 1 & & \\
\hline appropriate contexts for eating foods & categorization & & & & & 1 \\
\hline usual appearance of food & categorization & 1 & 1 & 1 & 1 & 2 \\
\hline typical combinations of foods or flavours & categorization & 1 & 1 & & & \\
\hline
\end{tabular}

Shaded areas in the table indicate that there is evidence in the literature that infants in the relevant age band use the specified learning strategy to learn about food. Blank cells indicate an absence of evidence in this age group. The number in each cell specifies the number of studies that have reported relevant evidence in this age group. 
familiarization constitutes a form of statistical learning. The learning of associations through flavor-flavor or FNL would similarly result from statistical learning over multiple encounters; and (iv) causal learning (the construction of causal explanations of the consequences of events). Gripshover and Markman (2013) report that 4-year olds reason causally about foods when learning about nutrition, but this form of learning has not been explored in children under 3 years, and is not considered by the literature reviewed here.

A further gap in the literature, aside from the question of "how" children learn about foods, is a comprehensive account of "what" they learn. Table 6 summarizes what we know children learn through each of the learning processes considered. The majority of studies have explored factors relating to children's evaluations of foods (whether a food is liked, preferred, accepted into their diet, or rejected). A smaller number of studies have investigated children's learning about the characteristics of foods. Other components of the knowledge children acquire about food remain unexplored. How do children learn the names of foods, the cultural and social contexts in which foods are eaten, foods' origins and preparation methods, and skills related to eating (e.g., how to use a spoon)? These questions are clearly also relevant to the development of healthy eating habits.

This review article has identified and summarized the literature on how infants learn about food between weaning and 36 months of age, and has confirmed that the learning strategies that support children's development in other domains

\section{REFERENCES}

Addessi, E., Galloway, A. T., Visalberghi, E., and Birch, L. L. (2005). Specific social influences on the acceptance of novel foods in 2-5-year-old children. Appetite 45, 264-271. doi: 10.1016/j.appet.2005.07.007

Agostoni, C., Decsi, T., Fewtrell, M., Goulet, O., Kolacek, S., Koletzko, B., et al. (2008). Complementary feeding: a commentary by the ESPGHAN Committee on Nutrition. J. Pediatr. Gastroenterol. Nutr. 46, 99-110. doi: 10.1097/01.mpg.0000304464.60788.bd

Ahern, S. M., Caton, S. J., Bouhlal, S., Hausner, H., Olsen, A., Nicklaus, S., et al. (2013). Eating a rainbow. Introducing vegetables in the first years of life in 3 European countries. Appetite 71, 48-56. doi: 10.1016/j.appet.2013.07.005

Aldridge, V., Dovey, T. M., and Halford, J. C. G. (2009). The role of familiarity in dietary development. Dev. Rev. 29, 32-44. doi: 10.1016/j.dr.2008.11.001

Ashman, A. M., Collins, C. E., Hure, A. J., Jensen, M., and Oldmeadow, C. (2014). Maternal diet during early childhood, but not pregnancy, predicts diet quality and fruit and vegetable acceptance in offspring. Mater. Child Nutr. 12, 579-590. doi: $10.1111 / \mathrm{mcn} .12151$

Bandura, A. (1977). Social Learning Theory. Englewood Cliffs, NJ: Prentice-Hall.

Barends, C., de Vries, J. H. M., Mojet, J., and de Graaf, C. (2013). Effects of repeated exposure to either vegetables or fruits on infant's vegetable and fruit acceptance at the beginning of weaning. Food Qual. Prefer. 29, 157-165. doi: 10.1016/j.foodqual.2013.03.008

Beauchamp, G. K., and Moran, M. (1984). Acceptance of sweet and salty tastes in 2-year-old children. Appetite 5, 291-305. doi: 10.1016/S0195-6663(84)80002-1

Birch, L. L. (1980). Effects of peer models' food choices and eating behaviors on preschoolers' food preferences. Child Dev. 51, 489-496. doi: 10.2307/1129283

Birch, L. L., and Anzman, S. L. (2010). Learning to eat in an obesogenic environment: a developmental systems perspective on childhood obesity. Child Dev. Perspect. 4, 138-143. doi: 10.1111/j.1750-8606.2010.00132.x

Birch, L. L., and Doub, A. E. (2014). Learning to eat: Birth to age 2 years. Am. J. Clin. Nutr. 99, 723S-728S. doi: 10.3945/ajcn.113.069047 are applicable to how children learn about food. The summary allows strong conclusions to be drawn in terms of the powerful role of familiarization with foods through repeated exposure; in our view, these can be communicated with confidence to parents and health workers who support and advise on the weaning process. The review has also highlighted gaps in our understanding of the operation of other learning strategies where the evidence is less clear-cut but clearly warrants further investigation. Given the well-documented relationship between children's early food preferences and food-related behaviors and dietary habits and health in later life, we would encourage a systematic interrogation of the questions this review has raised.

\section{AUTHOR CONTRIBUTIONS}

MM conducted the systematic search and wrote the first version of the introduction, methodology section and part of the results section. CV and HW conceptualized the review. CV wrote part of the introduction, results and discussion. HW wrote part of the results and discussion. SC wrote part of the results and discussion. $\mathrm{CH}$ wrote part of the results section and discussion section. $\mathrm{CH}$ edited the full paper. All authors contributed to and approved the final manuscript.

\section{FUNDING}

$\mathrm{MM}, \mathrm{CV}$, and HW are employees of Nutricia Research.

Birch, L. L., Gunder, L., Grimm-Thomas, K., and Laing, D. G. (1998). Infants' consumption of a new food enhances acceptance of similar foods. Appetite 30, 283-295. doi: 10.1006/appe.1997.0146

Birch, L. L., McPhee, L., Shoba, B. C., Pirok, E., and Steinberg, L. (1987). What kind of exposure reduces children's food neophobia? Looking vs. tasting. Appetite 9 , 171-178. doi: 10.1016/S0195-6663(87)80011-9

Blossfeld, I., Collins, A., Boland, S., Baixauli, R., Kiely, M., and Delahunty, C. (2007a). Relationships between acceptance of sour taste and fruit intakes in 18-month-old infants. Br. J. Nutr. 98, 1084-1091. doi: 10.1017/S0007114507749231

Blossfeld, I., Collins, A., Kiely, M., and Delahunty, C. (2007b). blossand the role of early experiences. Food Qual. Prefer. 18, 396-404. doi: 10.1016/j.foodqual.2006.03.022

Bouhlal, S., Issanchou, S., Chabanet, C., and Nicklaus, S. (2014). 'Just a pinch of salt': an experimental comparison of the effect of repeated exposure and flavorflavor learning with salt or spice on vegetable acceptance in toddlers. Appetite 83, 209-217. doi: 10.1016/j.appet.2014.07.032

British Dietetic Association (2016). Food Fact Sheet, Complementary Feeding (Weaning). Available online at: https://www.bda.uk.com/foodfacts/ WeaningYourChild.pdf.

Brown, S. D., and Harris, G. (2012a). Disliked food acting as a contaminant during infancy. A disgust based motivation for rejection. Appetite 58, 535-538. doi: 10.1016/j.appet.2012.01.010

Brown, S. D., and Harris, G. (2012b). A theoretical proposal for a perceptually driven, food-based disgust that can influence food acceptance during early childhood. Int. J. Child Health Nutr. 2012, 1-10. doi: 10.6000/1929-4247.2012.01.01.01

Brunstrom, J. M., Mitchell, G. L., and Baguley, T. S. (2005). Potential early-life predictors of dietary behaviour in adulthood: a retrospective study. Int. J. Obes. 29, 463-474. doi: 10.1038/sj.ijo.0802890

Cashdan, E. (1994). A sensitive period for learning about food. Hum. Nat. 5, 279-291. doi: 10.1007/BF02692155 
Cashdan, E. (1998). Adaptiveness of food learning and food aversions in children. Soc. Sci. Inform. 37, 613-632. doi: 10.1177/053901898037004003

Caton, S. J., Ahern, S. M., and Hetherington, M. M. (2011). Vegetables by stealth. An exploratory study investigating the introduction of vegetables in the weaning period. Appetite 57, 816-825 doi: 10.1016/j.appet.2011.05.319

Caton, S. J., Ahern, S. M., Remy, E., Nicklaus, S., Blundell, P., and Hetherington, M. M. (2013). Repetition counts: repeated exposure increases intake of a novel vegetable in UK pre-school children compared to flavour-flavour and flavour-nutrient learning. Br. J. Nutr. 109, 2089-2097. doi: $10.1017 /$ S0007114512004126

Caton, S. J., Blundell, P., Ahern, S. M., Nekitsing, C., Olsen, A., Møller, P., et al. (2014). Learning to eat vegetables in early life: the role of timing, age and individual eating traits. PLoS ONE 9:e97609. doi: 10.1371/journal.pone.0097609

Clayton, D. A. (1978). Socially facilitated behavior. Q. Rev. Biol. 53, 373-392. doi: $10.1086 / 410789$

Coulthard, H., Harris, G., and Emmett, P. (2010). Long-term consequences of early fruit and vegetable feeding practices in the United Kingdom. Public Health Nutr. 13, 2044-2051. doi: 10.1017/S1368980010000790

Coyle, S., Arnold, H. M., Goldberg-Arnold, J. S., Rubin, D. C., and Hall, W. G. (2000). Olfactory conditioning facilitates diet transition in human infants. Dev. Psychobiol. 37, 144-152. doi: 10.1002/1098-2302(200011)37:3<144::AIDDEV3>3.0.CO;2-Z

Davis, C. M. (1939). Results of the self-selection of diets by young children. Can. Med. Assoc. J. 41, 257-261.

Desor, J. A., Maller, O., and Andrews, K. (1975). Ingestive responses of human newborns to salty, sour, and bitter stimuli. J. Comp. Physiol. Psychol. 89, 966-970. doi: 10.1037/h0077171

de Wild, V. W., de Graaf, C., and Jager, G. (2013). Effectiveness of flavour nutrient learning and mere exposure as mechanisms to increase toddler's intake and preference for green vegetables. Appetite 64, 89-96. doi: 10.1016/j.appet.2013.01.006

Dovey, T. M., Staples, P. A., Gibson, E. L., and Halford, J. C. G. (2008). Food neophobia and 'picky/fussy' eating in children: a review. Appetite 50, 181-193. doi: 10.1016/j.appet.2007.09.009

Edelson, L. R., Mokdad, C., and Martin, N. (2016). Prompts to eat novel and familiar fruits and vegetables in families with 1-3 year-old children: relationships with food acceptance and intake. Appetite 99, 138-148. doi: 10.1016/j.appet.2016.01.015

Faith, M. S. (2005). Development and modification of child food preferences and eating patterns: behavior genetics strategies. Int. J. Obes. 29, 549-556. doi: $10.1038 /$ sj.ijo.0802981

Fallon, A. E., and Rozin, P. (1983). The psychological bases of food rejections by humans. Ecol. Food Nutr. 13, 15-26. doi: 10.1080/03670244.1983.9990728

Fallon, A. E., Rozin, P., and Pliner, P. (1984). The child's conception of food: the development of food rejections with special reference to disgust and contamination sensitivity. Child Dev. 55, 566-575. doi: 10.2307/1129968

Fivush, R., Gray, J. T., and Fromhoff, F. A. (1987). Two-year-old talk about the past. Cogn. Dev. 2, 393-409. doi: 10.1016/S0885-2014(87)80015-1

Forestell, C. A., and Mennella, J. A. (2007). Early determinants of fruit and vegetable acceptance. Pediatrics 120, 1247-1254. doi: 10.1542/peds.2007-0858

Gerrish, C. J., and Mennella, J. A. (2001). Flavor variety enhances food acceptance in formula-fed infants. Am. J. Clin. Nutr. 73, 1080-1085.

Goswami, U. (ed.). (2008a). Blackwell Handbook of Childhood Cognitive Development. Malden, MA: John Wiley and Sons.

Goswami, U. (2008b). Cognitive development: The learning brain. New York, NY: Psychology Press.

Gregory, J. E., Paxton, S. J., and Brozovic, A. M. (2010). Maternal feeding practices, child eating behaviour and body mass index in preschool-aged children: a prospective analysis. Int. J. Behav. Nutr. Phys. Activ. 7:55. doi: 10.1186/1479-5868-7-55

Gripshover, S. J., and Markman, E. M. (2013). Teaching young children a theory of nutrition: conceptual change and the potential for increased vegetable consumption. Psychol. Sci. 24, 1541-1553. doi: 10.1177/0956797612474827

Hamlin, J. K., and Wynn, K. (2012). Who knows what's good to eat? Infants fail to match the food preferences of antisocial others. Cogn. Dev. 27, 227-239. doi: 10.1016/j.cogdev.2012.05.005
Hammer, L. D. (1992). The development of eating behavior in childhood. Pediatr. Clin. North Am. 39, 379-394. doi: 10.1016/S0031-3955(16)38334-1

Harper, L. V., and Sanders, K. M. (1975). The effect of adults' eating on young children's acceptance of unfamiliar foods. J. Exp. Child Psychol. 20, 206-214. doi: 10.1016/0022-0965(75)90098-3

Harris, G., and Booth, D. A. (1987). Infants' preference for salt in food: its dependence upon recent dietary experience. J. Reprod. Infant Psychol. 5, 97-104. doi: 10.1080/02646838708403479

Hausner, H., Olsen, A., and Moller, P. (2012). Mere exposure and flavour-flavour learning increase 2-3 year-old children's acceptance of a novel vegetable. Appetite 58, 1152-1159. doi: 10.1016/j.appet.2012.03.009

Heath, P., Houston-Price, C., and Kennedy, O. B. (2014). Let's look at leeks! Picture books increase toddlers' willingness to look at, taste and consume unfamiliar vegetables. Front. Psychol. 5:191. doi: 10.3389/fpsyg.2014.00191

Houston-Price, C., Butler, L., and Shiba, P. (2009). Visual exposure impacts on toddlers' willingness to taste fruits and vegetables. Appetite 53, 450-453. doi: 10.1016/j.appet.2009.08.012

Jackson, C., Cheater, F. M., and Reid, I. (2008). A systematic review of decision support needs of parents making child health decisions. Health Expect. 11, 232-251. doi: 10.1111/j.1369-7625.2008.00496.x

Johnson, S. L., McPhee, L., and Birch, L. L. (1991). Conditioned preferences: young children prefer flavors associated with high dietary fat. Physiol. Behav. 50, 1245-1251. doi: 10.1016/0031-9384(91)90590-K

Kalat, J. W., and Rozin, P. (1973). "Learned safety" as a mechanism in longdelay taste-aversion learning in rats. J. Comp. Physiol. Psychol. 83, 198-207. doi: $10.1037 / \mathrm{h} 0034424$

Kolb, D. A. (ed.). (1984). Experiential Learning: Experience As the Source of Learning and Development. Englewood Cliffs, NJ: Prentice-Hall.

Kral, T. V., and Faith, M. S. (2007). Child eating patterns and weight regulation: a developmental behaviour genetics framework. Acta Paediatr. Suppl. 96, 29-34. doi: 10.1111/j.1651-2227.2007.00167.x

Laskarzewski, P., Morrison, J. A., Khoury, P., Kelly, K., Glatfelter, L., Larsen, R., et al. (1980). Parent-child nutrient intake interrelationships in school children ages 6 to 19: the Princeton School District Study. Am. J. Clin. Nutr. 33, $2350-2355$.

Lavin, T. A., and Hall, D. G. (2001). Domain effects in lexical development: learning words for foods and toys. Cogn. Dev. 16, 929-950. doi: 10.1016/S0885-2014(02)00070-9

Lipsitt, L. P., Crook, C., and Booth, C. A. (1985). The transitional infant: behavioral development and feeding. Am. J. Clin. Nutr. 41(2 Suppl.), 485-496.

Lumeng, J. C., and Hillman, K. H. (2007). Eating in larger groups increases food consumption. Arch. Dis. Child. 92, 384-387. doi: 10.1136/adc.2006.103259

Lumeng, J. C., Zuckerman, M. D., Cardinal, T., and Kaciroti, N. (2005). The association between flavor labeling and flavor recall ability in children. Chem. Senses 30, 565-574. doi: 10.1093/chemse/bji050

Lundy, B., Field, T., Carraway, K., Hart, S., Malphurs, J., Rosenstein, M., et al. (1998). Food texture preferences in infants versus toddlers. Early Child Dev. Care 146, 69-85. doi: 10.1080/0300443981460107

Macario, J. F. (1991). Young children's use of color in classification: foods and canonically colored objects. Cogn. Dev. 6, 17-46. doi: 10.1016/0885-2014(91)90004-W

Maier, A., Chabanet, C., Schaal, B., Issanchou, S., and Leathwood, P. (2007). Effects of repeated exposure disliked vegetables in on acceptance of initially 7-month-old infants. Food Qual. Prefer. 18, 1023-1032. doi: 10.1016/j.foodqual.2007.04.005

Maier, A. S., Chabanet, C., Schaal, B., Leathwood, P. D., and Issanchou, S. N. (2008). Breastfeeding and experience with variety early in weaning increase infants' acceptance of new foods for up to two months. Clin. Nutr. 27, 849-857. doi: 10.1016/j.clnu.2008.08.002

Maier-Nöth, A., Schaal, B., Leathwood, P., and Issanchou, S. (2016). The lasting influences of early food-related variety experience: a longitudinal study of vegetable acceptance from 5 months to 6 years in two populations. PLoS ONE 11:e0151356. doi: 10.1371/journal.pone.0151356

Mareschal, D., and Quinn, P. C. (2001). Categorization in infancy. Trends Cogn. Sci. 5, 443-450. doi: 10.1016/S1364-6613(00)01752-6

McGowan, L., Croker, H., Wardle, J., and Cooke, L. J. (2012). Environmental and individual determinants of core and non-core food and drink intake in 
preschool-aged children in the United Kingdom. Eur. J. Clin. Nutr. 66, 322-328. doi: 10.1038/ejen.2011.224

Mennella, J. A., Forestell, C. A., Morgan, L. K., and Beauchamp, G. K. (2009). Early milk feeding influences taste acceptance and liking during infancy. Am. J. Clin. Nutr. 90, 780S-788S. doi: 10.3945/ajcn.2009.27462O

Mennella, J. A., Nicklaus, S., Jagolino, A. L., and Yourshaw, L. M. (2008). Variety is the spice of life: strategies for promoting fruit and vegetable acceptance during infancy. Physiol. Behav. 94, 29-38. doi: 10.1016/j.physbeh.2007.11.014

Mennella, J. A., and Ventura, A. K. (2011). Early feeding: setting the stage for healthy eating habits. Nestle Nutr. Workshop Ser. Pediatr. Progr. 68, 153-163. doi: $10.1159 / 000325783$

Mobini, S., Chambers, L. C., and Yeomans, M. R. (2007). Effects of hunger state on flavour pleasantness conditioning at home: flavour-nutrient learning vs. flavour-flavour learning. Appetite 48, 20-28. doi: 10.1016/j.appet.2006.05.017

Morton, H., Santich, B., and Worsley, A. (1996). Mothers' perspectives on the eating habits of two-year-olds: a pilot study. Austr. J. Nutr. Dietetics 53, 100-105.

Nehring, I., Kostka, T., Kries, R., and von Rehfuess, E. A. (2015). Impacts of in utero and early infant taste experiences on later taste acceptance: a systematic review. J. Nutr. 145, 1271-1279. doi: 10.3945/jn.114.203976

Nguyen, S. P. (2007a). An apple a day keeps the doctor away: children's evaluative categories of food. Appetite 48, 114-118 doi: 10.1016/j.appet.2006.06.001

Nguyen, S. P. (2007b). Cross-classification and category representation in children's concepts. Dev. Psychol. 43, 719-731. doi: 10.1037/0012-1649.43. 3.719

Nguyen, S. P. (2008). Children's evaluative categories and inductive inferences within the domain of food. Infant Child Dev. 17, 285-299. doi: 10.1002/icd.553

Nguyen, S. P., and Murphy, G. L. (2003). An apple is more than just a fruit: cross-classification in children's concepts. Child Dev. 74, 1783-1806. doi: 10.1046/j.1467-8624.2003.00638.x

Nicklaus, S., Boggio, V., Chabanet, C., and Issanchou, S. (2005). A prospective study of food variety seeking in childhood, adolescence and early adult life. Appetite 44, 289-297. doi: 10.1016/j.appet.2005.01.006

Piaget, J. (1953). The Origin of Intelligence in the Child. London: Routledge \& Kegan Paul.

Pliner, P. (2008). Cognitive schemas: how can we use them to improve children's acceptance of diverse and unfamiliar foods? Br. J. Nutr. 99(Suppl. 1), S2-S6. doi: $10.1017 /$ S0007114508892446

Pliner, P., and Pelchat, M. L. (1986). Similarities in food preferences between children and their siblings and parents. Appetite 7, 333-342. doi: 10.1016/S0195-6663(86)80002-2

Rakison, D. H., and Oakes, L. M. (eds.). (2003). Early Category and Concept Development: Making Sense of the Blooming Buzzing Confusion. New York, NY: Oxford University Press.

Remy, E., Issanchou, S., Chabanet, C., and Nicklaus, S. (2013). Repeated exposure of infants at complementary feeding to a vegetable puree increases acceptance as effectively as flavor-flavor learning and more effectively than flavor-nutrient learning. J. Nutr. 143, 1194-1200. doi: 10.3945/jn.113.175646

Ross, B. H., and Murphy, G. L. (1999). Food for thought: cross-classification and category organization in a complex real-world domain. Cogn. Psychol. 38, 495-553. doi: 10.1006/cogp.1998.0712

Rozin, P. (1990). Acquisition of stable food preferences. Nutr. Rev. 48, 106-113. doi: 10.1111/j.1753-4887.1990.tb02912.x

Rozin, P., Fallon, A., and Augustoni-Ziskind, M. (1985). The child's conception of food: the development of contamination sensitivity to "disgusting" substances. Dev. Psychol. 21:1075. doi: 10.1037/0012-1649.21.6.1075

Rozin, P., and Fallon, A. E. (1980). The psychological categorization of foods and non-foods: a preliminary taxonomy of food rejections. Appetite 1, 193-201. doi: 10.1016/S0195-6663(80)80027-4

Rozin, P., and Fallon, A. E. (1987). A perspective on disgust. Psychol. Rev. 94, 23-41. doi: 10.1037/0033-295X.94.1.23

Rozin, P., Hammer, L., Oster, H., Horowitz, T., and Marmora, V. (1986). The child's conception of food: differentiation of categories of rejected substances in the 16 months to 5 year age range. Appetite 7, 141-151. doi: 10.1016/S0195-6663(86)80014-9

Shutts, K., Condry, K. F., Santos, L. R., and Spelke, E. S. (2009). Core knowledge and its limits: the domain of food. Cognition 112, 120-140. doi: 10.1016/j.cognition.2009.03.005

Skinner, J., Carruth, B. R., Moran, J., Houck, K., Schmidhammer, J., Reed, A., et al. (1998). Toddlers' food preferences: concordance with family members' preferences. J. Nutr. Educ. 30, 17-22. doi: 10.1016/S0022-3182(98)70270-5

Skinner, J. D., Carruth, B. R., Bounds, W., and Ziegler, P. J. (2002). Children's food preferences: a longitudinal analysis. J. Am. Diet. Assoc. 102, 1638-1647. doi: 10.1016/S0002-8223(02)90349-4

Snow, C. W., and McGaha, C. G. (2003). Infant Development, 3rd Edn. New Jersey, NJ: Prentice Hall.

Spelke, E. S., and Kinzler, K. D. (2007). Core knowledge. Dev. Sci. 10, 89-96. doi: $10.1111 /$ j.1467-7687.2007.00569.x

Steiner, J. E. (1977). "Facial expressions of the neonate infant indicating the hedonics of food-related chemical stimuli," in Taste and Development: The Genesis of Sweet Preference, ed J. M. Weiffenbach (Washington, DC: U.S. Government Printing Office), 173-188.

Steiner, J. E. (1979). Human facial expressions in response to taste and smell stimulation. Adv. Child Dev. Behav. 13, 257-295. doi: 10.1016/S0065-2407(08)60349-3

Sullivan, S. A., and Birch, L. L. (1994). Infant dietary experience and acceptance of solid foods. Pediatrics 93, 271-277.

Vereecken, C. A., Keukelier, E., and Maes, L. (2004). Influence of mother's educational level on food parenting practices and food habits of young children. Appetite 43, 93-103. doi: 10.1016/j.appet.2004.04.002

Vereijken, C. M., Weenen, H., and Hetherington, M. M. (2011). Feeding infants and young children. From guidelines to practice - conclusions and future directions. Appetite 57, 839-843. doi: 10.1016/j.appet.2011. 07.009

Visalberghi, E., and Addessi, E. (2000). Seeing group members eating a familiar food enhances the acceptance of novel foods in capuchin monkeys. Anim. Behav. 60, 69-76. doi: 10.1006/anbe.2000.1425

Wardle, J., Carnell, S., and Cooke, L. (2005). Parental control over feeding and children's fruit and vegetable intake: how are they related? J. Am. Diet. Assoc. 105, 227-2324 doi: 10.1016/j.jada.2004.11.006

Wardle, J., and Cooke, L. (2008). Genetic and environmental determinants of children's food preferences. Br. J. Nutr. 99, S15-S21. doi: 10.1017/S000711450889246X

Wertz, A. E., and Wynn, K. (2014). Selective social learning of plant edibility in 6- and 18-month-old infants. Psychol. Sci. 25, 874-882. doi: $10.1177 / 0956797613516145$

World Health Organization (2009). Infant and Young Child Feeding: Model Chapter for Textbooks for Medical Students and Allied Health Professionals. Geneva: World Health Organization.

Zajonc, R. B. (1968). Attitudinal effects of mere exposure. J. Pers. Soc. Psychol. 9(Pt 2), 1-27. doi: $10.1037 / \mathrm{h} 0025848$

Conflict of Interest Statement: MM, CV, and HW are employees of Nutricia Research.

The other authors declare that the research was conducted in the absence of any commercial or financial relationships that could be construed as a potential conflict of interest.

Copyright (c) 2017 Mura Paroche, Caton, Vereijken, Weenen and Houston-Price. This is an open-access article distributed under the terms of the Creative Commons Attribution License (CC BY). The use, distribution or reproduction in other forums is permitted, provided the original author(s) or licensor are credited and that the original publication in this journal is cited, in accordance with accepted academic practice. No use, distribution or reproduction is permitted which does not comply with these terms. 